\title{
Decision Making Using Multicriteria Analysis: A Case Study of Decision Modeling Career in Education
}

\author{
Ioannis Dimitrakopoulos \\ Technological Educational Institute of Epirus, Greece \\ E-mail: jndimitr@yahoo.gr \\ Kostas Karamanis \\ Technological Educational Institute of Epirus, Greece \\ E-mail: kkaraman@teiep.gr
}

Received: June 6, 2017 Accepted: July 6, $2017 \quad$ Published: July 17, 2017

doi:10.5296/csbm.v4i2.11355 URL: http://dx.doi.org/10.5296/csbm.v4i2.11355

\begin{abstract}
The aim of this paper is to offer an applicable evaluation framework relating to the right choice of one's profession via his/her studies. The first part of the paper consists of the basic principles of Multicriteria Decision Making. To begin with, the paper initially focuses on the Macbeth Method. This helps to provide a perspective for procedural types of decisions in which various qualitative and quantitative aspects are incorporated. In the second part of the paper, the above-mentioned multicriteria method is applied to a "real-world" case concerning a specific case of a student, Eva. For this specific study, it is concluded that the factors of greatest importance that lead to choosing the University Eva finally chose, were four: the cost of undergraduate studies, the reputation-status of the University, its logistics and infrastructure and its interconnections with other Universities and other Academic Institutions.
\end{abstract}

Keywords: Social Science, Personnel Management, IT Management, Multi-Criteria Decision Making, MACBETH Method, Career 


\section{Introduction}

According to the theories of occupational decision -making and development it is maintained that the optimal decisions are based upon sound stances- behaviours leading to the right choice of career which in turn offer stability and satisfaction in one's life (Hilton, 1962; Gelatt, 1962; Tiedeman, 1963; Katz, 1963; Vroom, 1964; Kaldor \& Zytowski, 1969; Harren, 1979; Gati, 1986). Deciding on what career to follow is two-fold consisting of the mechanism of choice and the outcome of this mechanism that is, the decision or choice. One of the most popular approaches to studying educational intention is the Theory of Planned Behavior. The underlying assumption of the theory is that behavior is under volitional control namely, personal attraction to the behavior, subjective norms and perceived behavioral control explain much of the variance in Intention, in turn, explains a significant amount of behavioral variance (Sahinidis et al., 2014).

Therefore the right choices lead to the rational decision -making when it comes to facing the complexities of life and career matters. Many studies concluded that the factors influencing one in decision- making are grouped as follows (Yip \& Côté, 2013; Zeelemberg et al., 2008; Zeelemberg et al., 1998; Goldstein \& Hogarth, 1997; Rosenhead, 1996):

- Individual factors. It is about biological and hereditary factors, acquired, personal factors, ones related to personality, motivation, self- awareness and self-esteem as well as factors related to one's beliefs, stance in life and values or one's personal needs.

- Background or otherwise non personal factors. In this case we refer to one's family, school, community, the circumstances and context one is living that affect the person dramatically in taking decisions

- $\quad$ Factors relevant to the decision. These are external factors that are directly interrelated to the decision itself such as the quality and the quantity of information, the level of risk taking, time anxiety, the possibility of revising one's decision, the possible consequences of the decision etc.

The three ways according to Harren (1979) in which people usually take a decision are (Leong et al., 1987; Philips et al., 1985):

$>$ The rational mode. People take responsibility of their actions based on their rationale since their actions are conscious and they seek for information relevant to the decision -making, therefore they act responsibly.

The intuitive mode. It focuses on intuition rather than reasoning or rationale. The decisions are spontaneous and require little time, not much information or planning.

The reliant mode. When the decision-making relies on the opinions, wishes and expectations of others the reliant mode is used so as to deny any personal responsibility involved because the others are to blame for whatever the consequences of that choice are.

According to Tiederman \& O'Hara (1963) a balanced decision should involve elements of the three modes of decision-making. When a decision is sound and balanced it takes into account 
information from internal as well as external sources. The effectiveness of a decision depends on how well one knows himself / herself and his/her surroundings, environment. As we can notice, the decision makers generally are influenced by many factors, such as self-interest, personality, peer pressure (Mousiolis et al., 2015; Fernandez-Huerga, 2008; Rocha \& Ghoshal 2006; Enns \& McFarlin, 2003). In the same direction, Li \& Davies (2011) deals with some key issues in using and developing information systems for strategic marketing decisions and they are concluded that hybrid intelligent support systems, coupled with such techniques as group decision support and knowledge management, will have a part to play in support of strategic marketing decisions, with the decision makers as a core and in control. Nikolopoulos (2003) finding out that subjectivity plays a very important role in managerial decision making. Subjectivity differs in quantity and quality according to the characteristics of the company and the decision maker, and to the kind of decision to be taken. La Scalia et al. (2016) found out that fuzzy technique for order performance by similarity to ideal solution can be a useful decision-making tool combined with the automatable methodology for data acquisition.

There have been significant changes in the global economy during the last 30 years. Since the early 1980s a series of changes in the economy, social structure and way of life of peoples took place. It is without doubt, common knowledge, that the decision concerning what kind of studies and career one chooses is one of the most important and determining decisions taken in one's life (Karamanis \& Hyz, 2016). Due to their age students differ to one another in terms of readiness to take a sound decision concerning their future career (Super et al., 1996; Crites \& Savickas, 1995). The occupational development of people is not in line with their mental, physical, social or emotional development. Therefore experts on this field should be able to define the readiness of their students who are on the verge of taking a decision concerning their studies and career and further on choose among the available educational and occupational prospects.

The aim of this paper is the development of such methods and the support of such techniques that will help students take optimal decisions taking advantage of the information available. The resolution of multi- faceted real problems with the use of criteria renders the use of suitable "equipment" for decision-making imperative such as Multicriteria Decision Making. The basic principles of Multicriteria Decision Making are presented here and great emphasis is given on the MACBETH method. Based on this joint method, it presents an empirical application for sustainable road planning in choice of one's career by our students.

\section{Multicriteria Decision Analysis (MCDA) as a Decision Support System in a Complex Decision-Making Process}

\subsection{General}

During the last decades we have seen an increasing and widespread use of multicriteria analysis. The multicriteria methods are a complex and multidimensional process, which looks into all the criteria involved in the analytical process of defining the object of decision, construction of the model of preference, and support of that decision combining decisions under circumstances of certainty and uncertainty (David, 2009; Siskos, 2005; Figueira et al., 2002; Belton \& Stewart, 2002; Lahdelma et al., 2002, Bouyssou et al., 2000, Hokkanen, \& 


\section{Macrothink}

Case Studies in Business and Management

ISSN 2333-3324

2017, Vol. 4, No. 2

Salminen, 1997; Roy \& Bouyssou, 1993; Roy, 1985). These methods serve to make a complex multidimensional choice problem more transparent. They are usually called multiple criteria methods, and they pay particular attention to major constituents of choice problems, including (Nijkamp et al., 2002):

- the identification of relevant choice options

- the definition of appropriate evaluation criteria (emanating from conflicting objectives)

- assessment of the numerical value of each evaluation criterion for each choice option

- the collection of measurable prior information about each of the relevant decision criteria (e.g., by means of weights or interactive computer methods)

- the identification of the relevant decision level or of the proper institutional decision procedure (in case of a multi-actor choice situation)

- the specification of a suitable measurement scale for the available information (e.g. ratio, ordinal or fuzzy information).

The multicriteria analysis is deployed in order to support the decision-making with emphasis on the following (Anwar et al., 2014; Montibeller \& Franco, 2011; Franco \& Rouwette, 2011; Franco \& Montibeller, 2010):

- both the concept of decision and the process of taking it,

- the basic characteristics of the decision as well as its long-term consequences,

- the discontinuity characterizing the creation and negotiation of decisions.

Thus, the multicriteria methodology for the support of the decision should encompass the following gradual stages (Richard, 1981):

a. Preliminary diagnosis,

b. Choice of fields and criteria,

c. Implementation of this reasoning,

d. Plan selection for execution,

e. Convergence of feedback cycles.

The problem of classification during the multicriteria decision analysis is tackled by placing the data of all the alternative actions into categories. The classification is achieved by examining the value of the attributes of these alternatives via predetermined rules. There are three basic categories according to the research approaches of the classification problem in the international bibliography (Manski, 2004; Mcfadden, 1981; Manski, 1980):

- $\quad$ statistics and econometrics,

- non parametric, 
- $\quad$ direct and indirect.

Nowadays there is plurality in terms of methods of multicriteria analysis. The most widely used techniques of such analysis require judgement, reason and differentiate in the way they combine the data with the result. Because of the bulk of complex information the aim of these techniques is to confront the difficulties the decision makers face in handling these information with consistency and reason. The applied techniques of multicriteria analysis can be used to define the most attractive choice, to classify the criteria, to numerate a limited number of choices, to separate acceptable from unacceptable reasoning (Hwang \& Yoon, 1981).

The application of mathematics in the applied techniques in every multicriteria decision problem focuses on the quantification of preferences and is mainly expressed through the concept of dual relationship. So the adoption of different mathematical models of dual relationships leads to different methodologies. In our days the methods of multicriteria analysis have evolved greatly due to the progress of the main three theoretical classes and other methods which are (Siskos \& Spyridakos, 1999):

a. the method based on functional models (theory of usefulness),

b. methods based on relational models (outranking relations) among the alternative actions,

c. interactive methods.

We will focus our attention on the Macbeth Method and will be concisely discussed in Sections 2.2.

\subsection{The Macbeth Method}

The MACBETH method of taking decisions (Measuring Attractiveness by a Categorical Based Evaluation Technique) was first presented in 1994 (Bana e Costa \& Vansnick, 1994) and constitutes a development and substantial improvement of the Analytic Hierarchy Process (AHP) of Thomas Saaty. It has been successfully implemented in a wide range of decision problems since by MACBETH method, the decision maker is called upon making comparisons every pair of criteria (pairwise comparisons) and the final model the criteria synthesis is a balanced average of marginal rates/index of attractiveness. The outcome of the attractiveness criteria should envelope the concept of consistent unit concessions (trade-off).

The goal of this method is the creation of quantitative models for the evaluation of the attractiveness of alternative solutions that belong to a finite group A. This is mathematically achieved by the solution of linear programs for the creation of value functions based on a process of question and answers between the analyst and the decision maker.

In the following Table 1 we can detect domination relationships among the actions which are expressed in a seven degree scale. Basically the scale requires the decision maker to verbally express the differences concerning attractiveness between two actions (criteria and/or alternatives). To this effect the process of quantification is achieved. 
Table 1. Scale of difference Attractiveness MACBETH

\begin{tabular}{|l|l|l|}
\hline Preference Rate $\left(\mathbf{C}_{\mathbf{k}}\right)$ & Difference of Attractiveness & Scale of Intensity $(\mathbf{k})$ \\
\hline C0 & Indifference & 0 \\
\hline C $\mathbf{1}$ & Little & 1 \\
\hline C $\mathbf{2}$ & Mild & 2 \\
\hline C $\mathbf{3}$ & Medium & 3 \\
\hline C $\mathbf{4}$ & Strong & 4 \\
\hline C $\mathbf{5}$ & Very Strong & 5 \\
\hline C $\mathbf{6}$ & Extreme Utmost & 6 \\
\hline
\end{tabular}

The process of questioning and answering is carried out in two stages. First the analyst classifies the data of the decision of the whole in the first phase $\mathrm{A}$ in descending order according to the decision-maker's preferences. Then in phase two the charts which compare the actions in pairs are filled out according to the decision-maker's preferences in line with the seven degree scale which is suggested by this method.

We have to take into consideration the following conditions of consistency so that the differences of attractiveness can be expressed (Bana e Costa \& Vasnick, 1999; Bana e Costa \& Vasnick, 1994):

$\forall a, b, c \in A$ with $a P b$ and $b P c$ and $\forall k_{v} k^{t} \in\{1,2,3,4,5,6\}$

$$
\begin{gathered}
\text { if }(a, b) \in C_{k} \text { and }(b, c) \in C k \\
\text { then }\left(a, c \in C_{k}\right) \text { with } k " \geq \max \{k, k,\}
\end{gathered}
$$

where $a, b$ and $c$ are the alternatives of the analysis and $k, k^{\prime}, k^{\prime \prime}$ are the rates of the MACBETH scale.

In effect, the preferences among alternatives are defined by the above conditions as follows (de Lima \& Damiani, 2009): "if alternative a is strongly preferred to alternative $b$ and alternative $b$ is medially preferred to alternative $c$ then the difference of attractiveness between alternative $a$ and $b$ can't be smaller than that between alternatives $a-b$ and $b-c$ ".

Consequently MACBETH method presupposes qualitative judgement/reasoning exclusively, concerning the differences in attractiveness so that the decision-maker can quantify the relevant value of the alternative actions. We are talking about an interactive approach that helps the decision-maker to estimate, evaluate the whole attractiveness aspect (global attractivity) of different actions bearing in mind multiple criteria. So the estimation and evaluation of the value (of attractiveness) of the alternatives in question is accomplished through a procedure of posing questions to the person who is going to take a decision-questions dealing with the expression of qualitative bilateral (non-numeric) comparisons of alternatives in a qualitative seven degree scale as mentioned above.

There has been a tremendous development in the supportive computer software in realizing 


\section{Macrothink}

Case Studies in Business and Management

ISSN 2333-3324

2017, Vol. 4, No. 2

MACBETH in the recent years (Bana e Costa \& Basnick, 1999). The latest development of the computer software (Bana e Costa et al., 2005) allows the modelling of problems and applications of multicriteria analysis and via the use of computer supports the direct creation of results such as the model of added value that expresses the preferences of the person who decides as well as sensitivity and robustness analysis.

The MACBETH computer software of multicriteria analysis is a very useful tool as it allows the:

- creation of value trees,

- development of descriptive criteria,

- grading of the choices concerning the criteria,

- creation of value functions,

- estimation of the importance of the criteria,

- $\quad$ sensitivity analysis,

- robustness analysis in terms of the relevant and real value of the alternatives.

The computer software is available on https://www.m-macbeth.com.

\section{A Case Study on the Eva's Case}

\subsection{The Problem}

Eva is an eighteen-year old high school student living in Preveza. Both her parents are civil servants, she has got a brother and her parent's financial situation is good. Eva wishes to become an architect and her parents encourage her to do so. Her performance at school is quite good and it is as follows:

- Mathematics: 14,

- Physics: 15,

- Chemistry: 16,

- Ancient Greek: 14,

- Modern Greek: 12,

- Foreign Languages: excellent knowledge of French, very good knowledge of English, good knowledge of Italian.

After discussion with the responsible Vocational Guidance School Consultant and her parents, taking into account her strong wish to realize her dream as well, she decides not to sit the Greek General Exams and to attend a University abroad instead. Her choice was based on the following data:

1). Her school performance does not allow her to have an entry in relevant of her preference 
University in Greece,

2). Her parents financial status gives the green light to her studying abroad and

3). Her good command of foreign languages allows her to study abroad as well.

\section{Eva's dilemma is: which University she should attend abroad.}

\subsection{Application of the MACBETH Computer Software}

The MACBETH approach will be applied as it was discussed in detail previously so that a decision will be taken considering the problem in question which is the optimal choice of studies abroad for Eva. Then the data of this application, the analysis, the resolution are presented and the final decision is to be taken.

Initially the decision-maker has to set the criteria upon which the attractiveness of the student's decision will be evaluated. These attractiveness criteria upon which Eva's decision was evaluated are the following four (4) which are illustrated in the tree of values we created in M-MACBETH:

1). k1 - cost of studies abroad,

2). k2 - reputation of the University,

3). k3-logistic infrastructure,

4). k4 - interconnections with other Universities and Institutions.

Defining the criteria allows subsequently that the nodes, the value tree of criteria and the three alternative options the student has, are registered: University U-F, University U-E, University U-I as in:

$$
\begin{gathered}
U-F=\{\text { University in France }\} \\
U-E=\{\text { University in England }\} \\
U-I=\{\text { University in Italy }\}
\end{gathered}
$$

In Figure 1 you can see the nodes, the value tree of criteria and the relevant options/choices. 


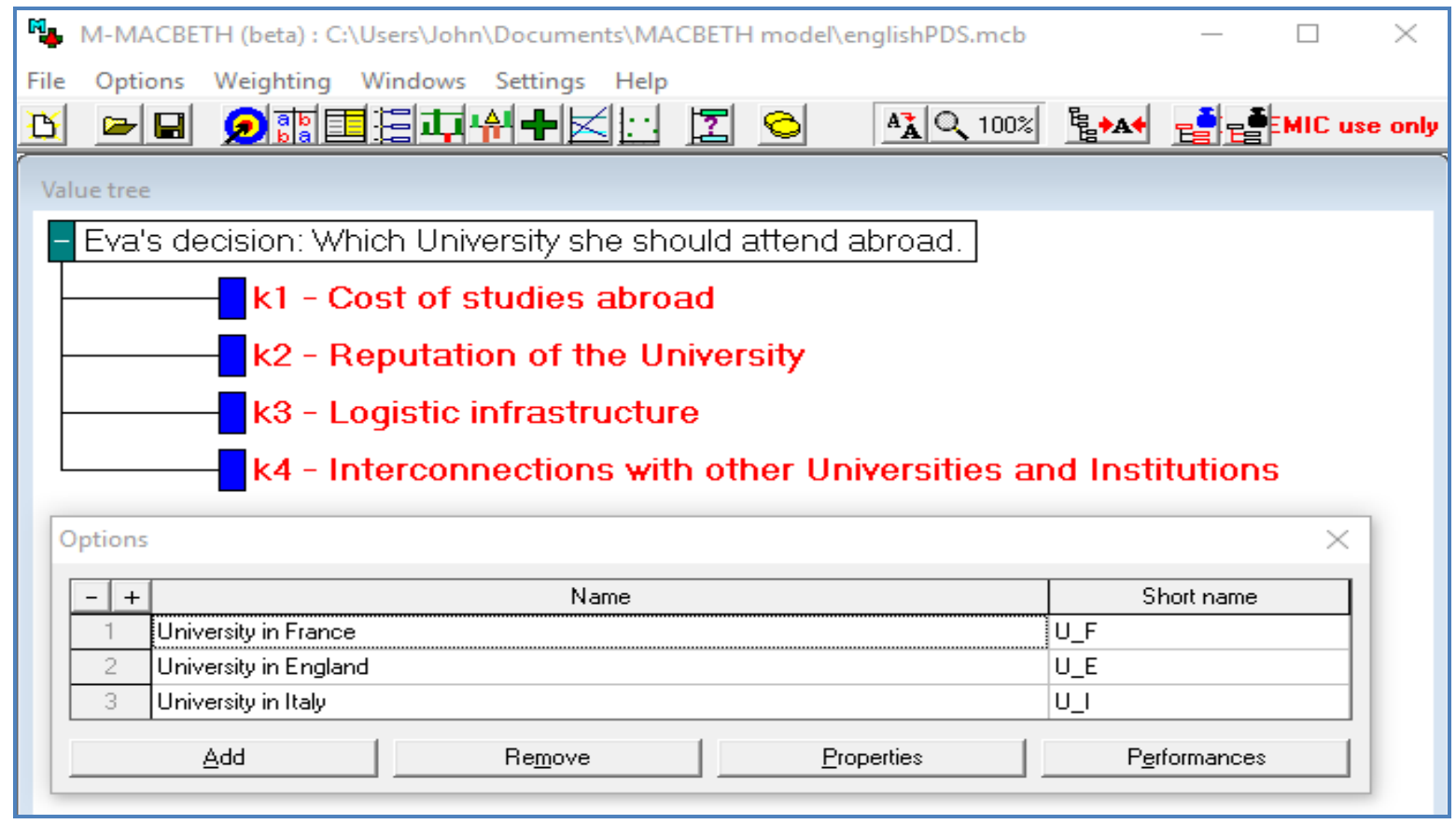

Figure 1. Nodes, the value tree of criteria and the relevant options/choices

The properties of the nodes of the value tree are defined as:

- Criterion k1-cost of undergraduate studies: It involves tuition fees and relevant costs such as that of accommodation, transportation and eating. This criterion is described quantitatively ranging from 10.000 Euros (the most attractive option) to $30.000 €$ (the least attractive option) per year (Figure 2).

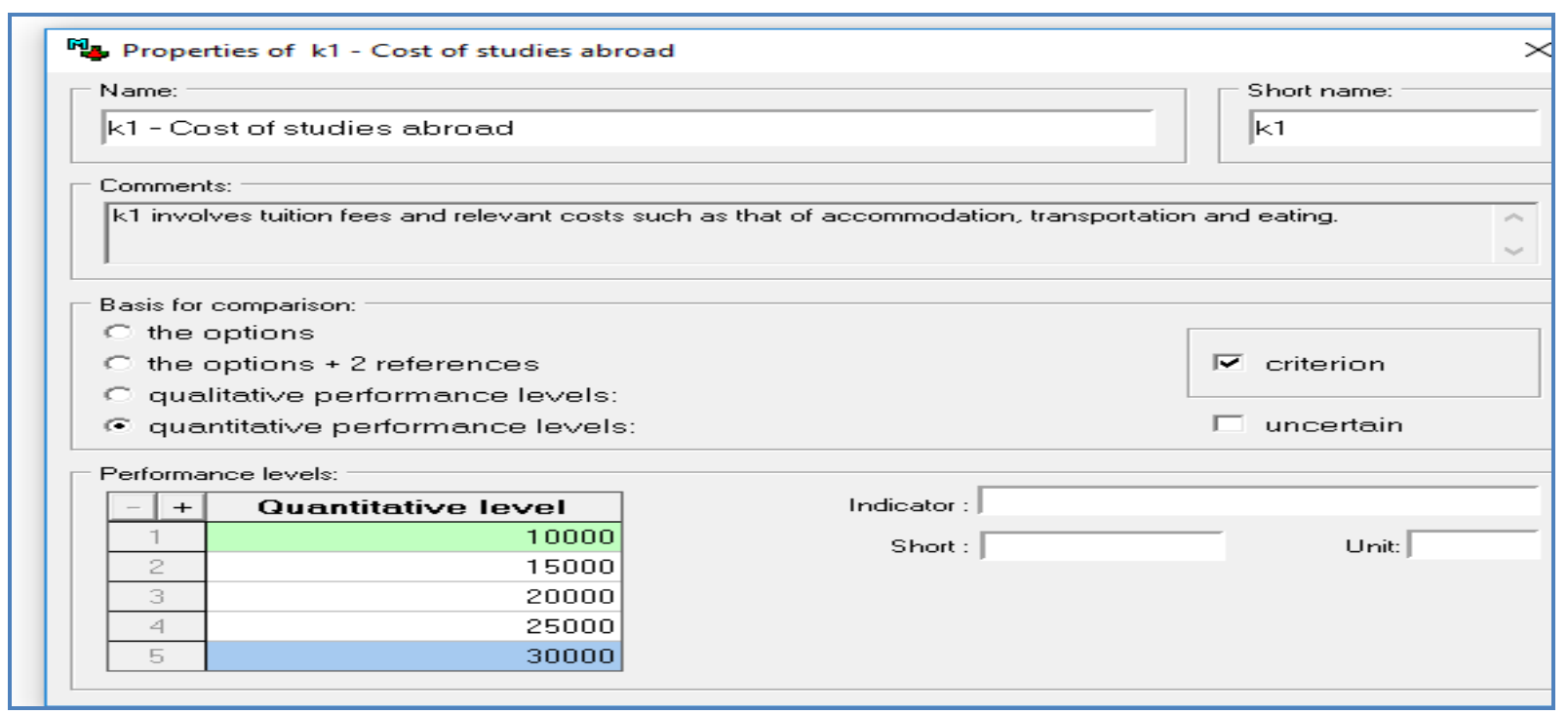

Figure 2. Properties of $\mathrm{k} 1$ - Cost of undergraduate studies 


\section{Macrothink}

Case Studies in Business and Management

ISSN 2333-3324

2017, Vol. 4, No. 2

- Criterion $k 2$-the reputation (status) of the University: It refers to the international recognition of the University, the quality of its syllabus, the professional standing of its professors, the multiannual tradition of the establishment, the possibility of realısing postgraduate studies or a doctoral degree (Figure 3).

\begin{tabular}{|c|c|c|c|c|c|}
\hline \multicolumn{5}{|c|}{ 미를 Properties of $k 2$ - Reputation of the University } & \\
\hline \multicolumn{2}{|l|}{ Name: } & \multirow{2}{*}{\multicolumn{4}{|c|}{$\begin{array}{l}\text { Short name: } \\
\text { k2 }\end{array}$}} \\
\hline \multicolumn{2}{|c|}{ k2 - Reputation of the University } & & & & \\
\hline \multicolumn{6}{|c|}{ - Comments: } \\
\hline \multicolumn{6}{|c|}{$\begin{array}{l}\text { K2 refers to the international recognition of the University, the quality of its syllabus, the professional standing of its } \\
\text { professors, the multiannual tradition of the establishment, the possibility of realtsing postgraduate studies or } a \\
\text { doctoral degree }\end{array}$} \\
\hline \multicolumn{6}{|c|}{ Basis for comparison: } \\
\hline \multicolumn{2}{|c|}{$\sigma$ the options +2 references } & \multicolumn{4}{|c|}{$\sqrt{ }$ criterion } \\
\hline \multicolumn{2}{|c|}{$\sim$ quantitative performance levels: } & \multicolumn{4}{|c|}{ F uncertain } \\
\hline \multicolumn{6}{|c|}{ - Performance levels: } \\
\hline \begin{tabular}{|l|l|}
- & + \\
\end{tabular} & \multicolumn{3}{|l|}{ Qualitative level } & \multicolumn{2}{|c|}{ Short } \\
\hline 1 & \multicolumn{3}{|l|}{ REPUTATION 1} & \multicolumn{2}{|c|}{ R1 } \\
\hline 2 & \multicolumn{3}{|l|}{ REPUTATION 2} & \multicolumn{2}{|c|}{$\mathrm{R} 2$} \\
\hline 3 & \multicolumn{3}{|l|}{ REPUTATION 3} & \multicolumn{2}{|c|}{ R3 } \\
\hline
\end{tabular}

Figure 3. Properties of $\mathrm{k} 2$ - The reputation of the University

- Criterion k3-Logistics infrastructure: It denotes the availability and accessibility of logistics infrastructure such as technological or computing infrastructure (computer labs, databases) reference works, a library (Figure 4).

\begin{tabular}{|c|c|c|c|}
\hline \multicolumn{3}{|c|}{ W. Properties of $k 3$ - Logistic infrastructure } & \\
\hline \multicolumn{2}{|c|}{ Name: } & \multirow{2}{*}{\multicolumn{2}{|c|}{$\left[\begin{array}{l}\text { Short name: } \\
\mathrm{k3}\end{array}\right.$}} \\
\hline \multicolumn{2}{|c|}{ k3-Logistic infrastructure } & & \\
\hline \multicolumn{4}{|c|}{ Comments: - } \\
\hline \multicolumn{3}{|c|}{$\begin{array}{l}\text { k3 denotes the availability and accessibility of logistics infrastructure such as technological or computing } \\
\text { infrastructure [computer labs, databases] reference works, a library }\end{array}$} & $\hat{\imath}$ \\
\hline \multicolumn{4}{|c|}{ Basis for comparison: } \\
\hline \multicolumn{4}{|c|}{$\sigma$ the options } \\
\hline \multicolumn{2}{|c|}{$\sim$ the options +2 references } & \multicolumn{2}{|l|}{$\sqrt{ }$ criterion } \\
\hline \multicolumn{2}{|c|}{ - qualitative performance levels: } & \multirow{2}{*}{\multicolumn{2}{|c|}{ Г uncertain }} \\
\hline$\sigma$ que & antitative performance levels: & & \\
\hline \multicolumn{4}{|c|}{ - Performance levels: } \\
\hline \begin{tabular}{l|l|l}
- & + \\
\end{tabular} & \multicolumn{2}{|l|}{ Qualitative level } & Short \\
\hline 1 & \multicolumn{2}{|l|}{ Logistic infrastructure 1} & INF1 \\
\hline 2 & \multicolumn{2}{|l|}{ Logistic infrastructure 2} & INF2 \\
\hline 3 & \multicolumn{2}{|l|}{ Logistic infrastructure 3} & INF3 \\
\hline
\end{tabular}

Figure 4. Properties of k3-Logistics infrastructure 


\section{Macrothink}

Case Studies in Business and Management

ISSN 2333-3324

2017, Vol. 4, No. 2

- Criterion k4-interconnections with other Universities and Scientific Institutions: This refers to how flexible the University is in terms of interconnecting and cooperating with other national and international Educational Institutions and Universities as well as Scientific Institutions (Figure 5).

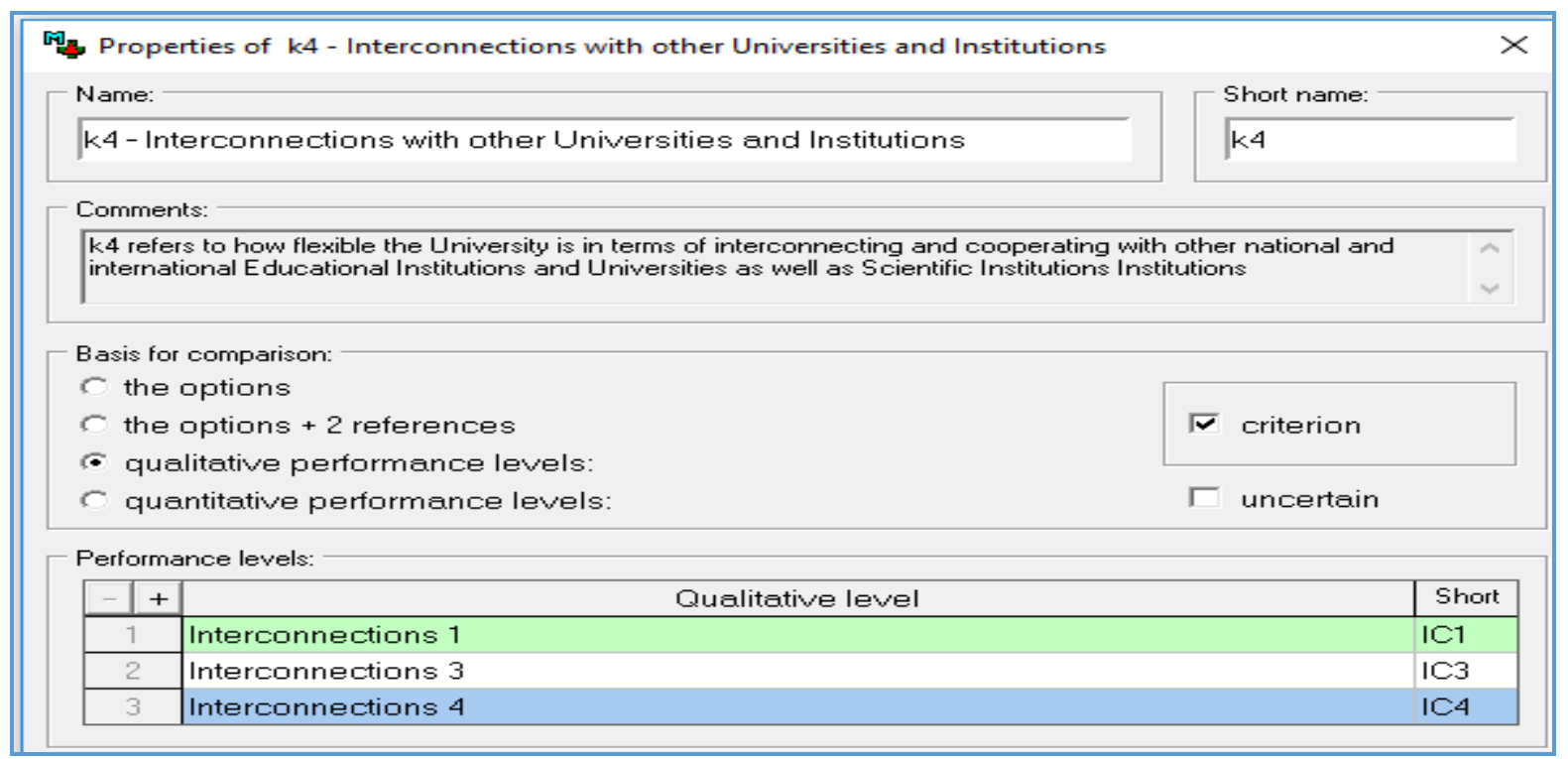

Figure 5. Properties of k4-Interconnections of the University

The evaluation of criteria $\mathrm{k} 2, \mathrm{k} 3$ and $\mathrm{k} 4$ is described in a qualitative manner. Thus, the person who is to take a decision gives to each option one and only one description for each criterion.

Then the Figure 6 of performances is registered. For example, the option U-F (University in France) was linked by the analyst as follows: $22.000 €$ costs, REPUTATION $1-\mathrm{R} 1$ ( long tradition in architectural studies, a great number of prestigious professors, many possible mentors, the international status of the University very good), LOG. INFRASTRUCTURE 1-INF1 (very well equipped laboratories, availability of technological or computing infrastructure, databases, library) and INTERCONNECTIONS 3 (morning lectures during the morning, the courses are carried out in French, alternative language: English).

\begin{tabular}{|c|c|c|c|c|}
\hline \multicolumn{4}{|c|}{ Table af perfarramés } & $\infty$ \\
\hline 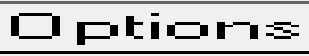 & $1=7$ & $1=-2$ & $1=-3$ & $1=4$ \\
\hline 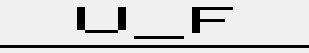 & ニ示口1口 & $F \mathbf{7}$ & $I F-1 F I$ & 1 E- \\
\hline IIE & 7 こ回口 & $F:=$ & IF- $1 F=$ & IE=1 \\
\hline L_I & 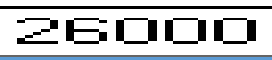 & F: : & IF-1F: & $1 E-4$ \\
\hline
\end{tabular}

Figure 6. Table of performances 


\section{Macrothink}

Case Studies in Business and Management

ISSN 2333-3324

2017, Vol. 4, No. 2

The difference in attractiveness for the criterion related to the cost of undergraduate studies (judgment) is defined as such: the most attractive and the least attractive levels are compared to the next level of attractiveness, the less attractive level. Then the most attractive level is compared to all the other levels and afterwards the most attractive is compared to the second most attractive level, then the second is compared to the third and so on and so forth. The verbal scale is formed separately for each criterion depending on the range and the gap/difference of ratings $(5000 €)$. In case the ratings are exactly the same there is no comparison carried out between them because there's no issue of difference in attractiveness. Figure 7 depicts the differences of attractiveness for criterion $\mathrm{k} 1$ - cost of undergraduate studies.

\begin{tabular}{|c|c|c|c|c|c|c|c|}
\hline \multicolumn{7}{|c|}{ n1 - Cost of studies abroad } & \multirow[b]{2}{*}{ extreme } \\
\hline 畻 & 10000 & 15000 & 20000 & 25000 & 30000 & $\begin{array}{l}\text { Current } \\
\text { scale }\end{array}$ & \\
\hline 10000 & no & moderate & strg-vstr & extreme & vstrg-extr & 100.00 & Y. strong \\
\hline 15000 & & no & moderate & strg-vstr & extreme & 76.92 & strong \\
\hline 20000 & & & no & strong & $\checkmark$. strong & 53.85 & moderate \\
\hline 25000 & & & & no & moderate & 23.08 & weak \\
\hline 30000 & & & & & no & 0.00 & Yery weak \\
\hline \multicolumn{8}{|c|}{ Consistent judgements } \\
\hline & & 8 okd 7 & & $\stackrel{H}{\text { DIFF }}$ & 距 & & \\
\hline
\end{tabular}

Figure 7. Differences of attractiveness $k 1$ - cost of undergraduate studies

Based on the patterns of decisions for the differences of attractiveness in criteria the MACBETH computer software forms a pericardial scale that can be evaluated in linear representation. Figure 8 represents the pericardial linear scale for criterion k1.

\begin{tabular}{|c|c|c|c|}
\hline & 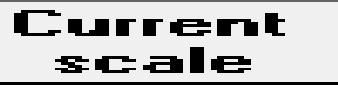 & 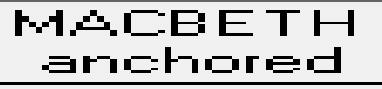 & 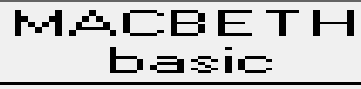 \\
\hline 7 口а口冋 & 1ロロ - ロロ & 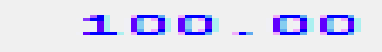 & $1 \equiv-\square \square$ \\
\hline ביםロ & $7 \pm-3 z$ & $7 \leq-9 z$ & $10-00$ \\
\hline ㅁㅁㅁㅁㅁ & $\equiv \equiv-\equiv \equiv$ & $\equiv \equiv-\equiv \equiv$ & $7-00$ \\
\hline 름ㅁㅁㅁㅁ & $z \equiv-\square \equiv$ & $z \equiv-\square \equiv$ & $\exists-a \square$ \\
\hline : & $\square-\square \square$ & $\square-\square \square$ & $\square-\square \square$ \\
\hline
\end{tabular}

Figure 8. Pericardial scale for criterion $\mathrm{k} 1$ 


\section{Ml Macrothink}

Case Studies in Business and Management

ISSN 2333-3324

2017, Vol. 4, No. 2

The decision-maker was asked to classify the criteria from the most important to the least important (Table 2) and to fill in the twofold criteria comparisons (Figure 9) as these are expressed in the MACBETH evaluation scale in order to estimate the importance of the 4 criteria (Table 3). The result of this is the importance of the criteria (Figure 10).

Table 2. MACBETH evaluation scale

\begin{tabular}{|l|l|}
\hline C0 & no difference \\
\hline C1 & very weak difference \\
\hline C2 & weak difference \\
\hline C3 & moderate difference \\
\hline C4 & strong difference \\
\hline C5 & very strong difference \\
\hline C6 & extreme difference \\
\hline
\end{tabular}

Table 3. Criteria classification according to their importance

\begin{tabular}{|l|l|l|}
\hline $\mathbf{1}$ & $\mathbf{k 1}$ & cost of studies abroad \\
\hline $\mathbf{2}$ & $\mathrm{k} 2$ & reputation of the University \\
\hline $\mathbf{3}$ & $\mathrm{k} 3$ & logistic infrastructure \\
\hline $\mathbf{4}$ & $\mathrm{k} 4$ & interconnections with other Universities and Institutions \\
\hline
\end{tabular}

\begin{tabular}{|c|c|c|c|c|c|c|c|}
\hline \multicolumn{7}{|c|}{ Weighting (Eva's decision: Which University she should attend abroad.) } & $\times$ \\
\hline 艒 & [k1] & [k2] & [k3] & [k4] & [ all lower ] & $\begin{array}{l}\text { Current } \\
\text { scale }\end{array}$ & \multirow{2}{*}{$\begin{array}{c}\text { extreme } \\
\text { y. strong }\end{array}$} \\
\hline [k1] & no & moderate & moderate & strong & v. strong & 43.48 & \\
\hline [k2] & & no & moderate & moderate & moderate & 30.43 & strong \\
\hline [k3] & & & no & weak & moderate & 17.39 & moderate \\
\hline [k4] & & & & $m$ & Neal & 870 & weak \\
\hline & & & & & & & very weak \\
\hline [ all lower ] & & & & & no & 0.00 & \multirow[t]{2}{*}{ no } \\
\hline \multicolumn{7}{|c|}{ Consistent judgements } & \\
\hline & & & & 思 & 楳福? & & \\
\hline
\end{tabular}

Figure 9. Two fold comparisons of the criteria in the MACBETH evaluation scale

In order to specify and define the importance of the criteria, twofold comparisons are carried out and are expressed in the MACBETH evaluation scale. Initially the decision-maker is 
asked to evaluate his option which is neutral to each and every one of the criteria and respond by qualitative judgments in questions like: "in the overall differences of attractiveness of each criterion how much should a situation which is neutral be placed further on, in order to be classified as attractive". Then the analyst is called upon to compare the most attractive situation with the next following most attractive situation, by answering the question of how much more attractive a situation is from neutral to better from one criterion to another. The comparisons of attractiveness among the criteria as well as the results of their importance are very well portrayed in the software as follows (Figure10).

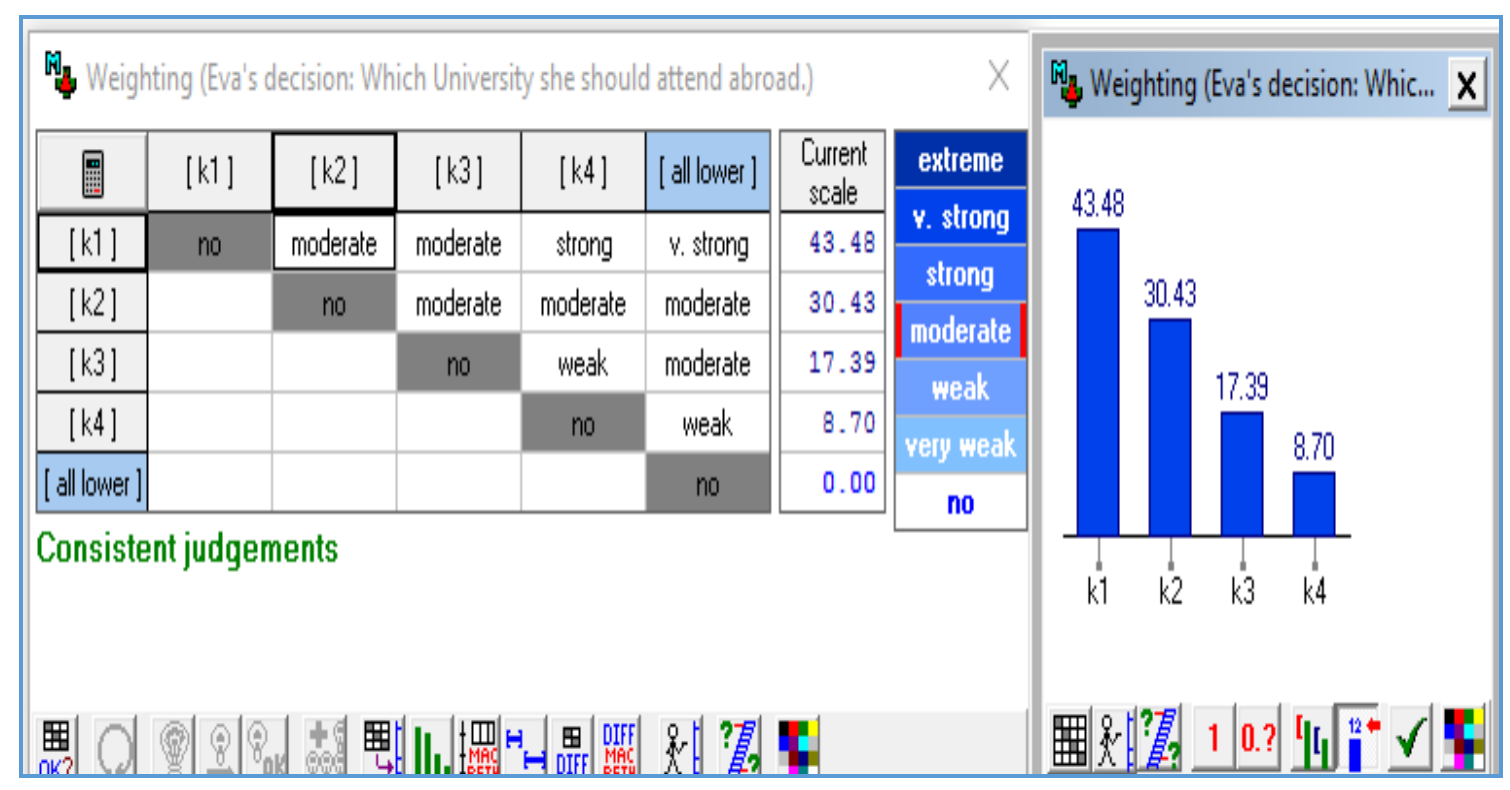

Figure 10. Chart of attractiveness and scale of importance

\subsection{Final Results and References}

Based on all the above we've come up with a chart of all the sub-ratings of each criterion (Table 4).

Table 4. Importance of criteria

\begin{tabular}{|l|l|l|}
\hline & Criterion & Weighting Factor \\
\hline k1 & Cost of studies abroad & 43,48 \\
\hline k2 & Reputation of the University & 30,43 \\
\hline k3 & Logistic infrastructure & 17,39 \\
\hline k4 & Interconnections with other Universities and Institutions & 8,70 \\
\hline
\end{tabular}




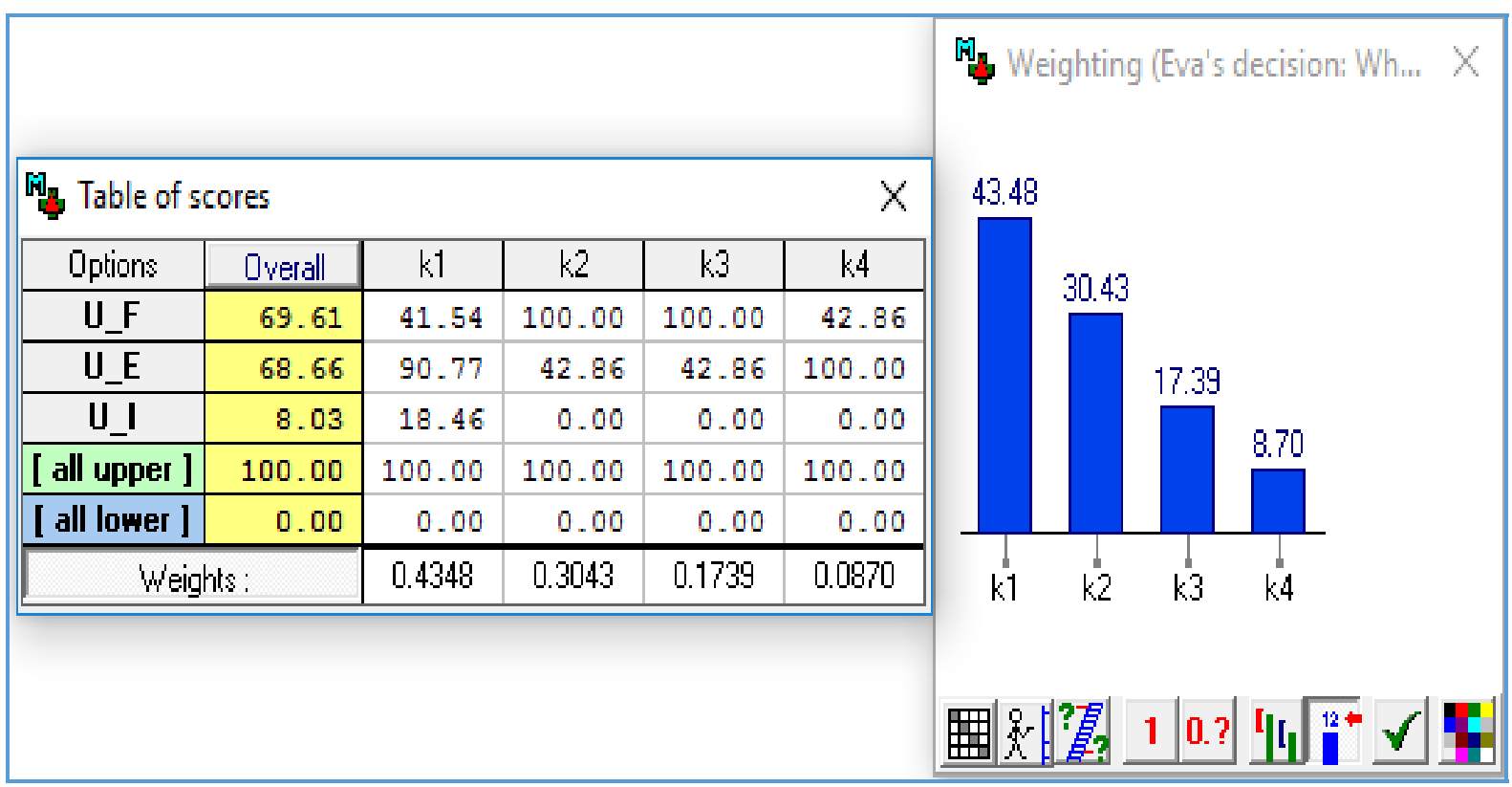

Figure 11. Final table of scores and performance (weighting) of the best University

Figure 11 gives us the final results of the candidates' choices as these were derived by M-MACBETH. In the table of scores, we see the total scoring/rating each prospective University gathered keeping in mind the sub-ratings in each criterion. We note that the University in France (U-F) gets the highest score $(69,61)$, the University in England comes second (U-E) with a small difference in scoring $(68,66)$ and last is the University in Italy (U-I) with a very low score $(8,03)$.

The above results are also depicted in the Overall Thermometer where we see that the Universities U-F and U-E dramatically differ from University U-I (Figure 12). 


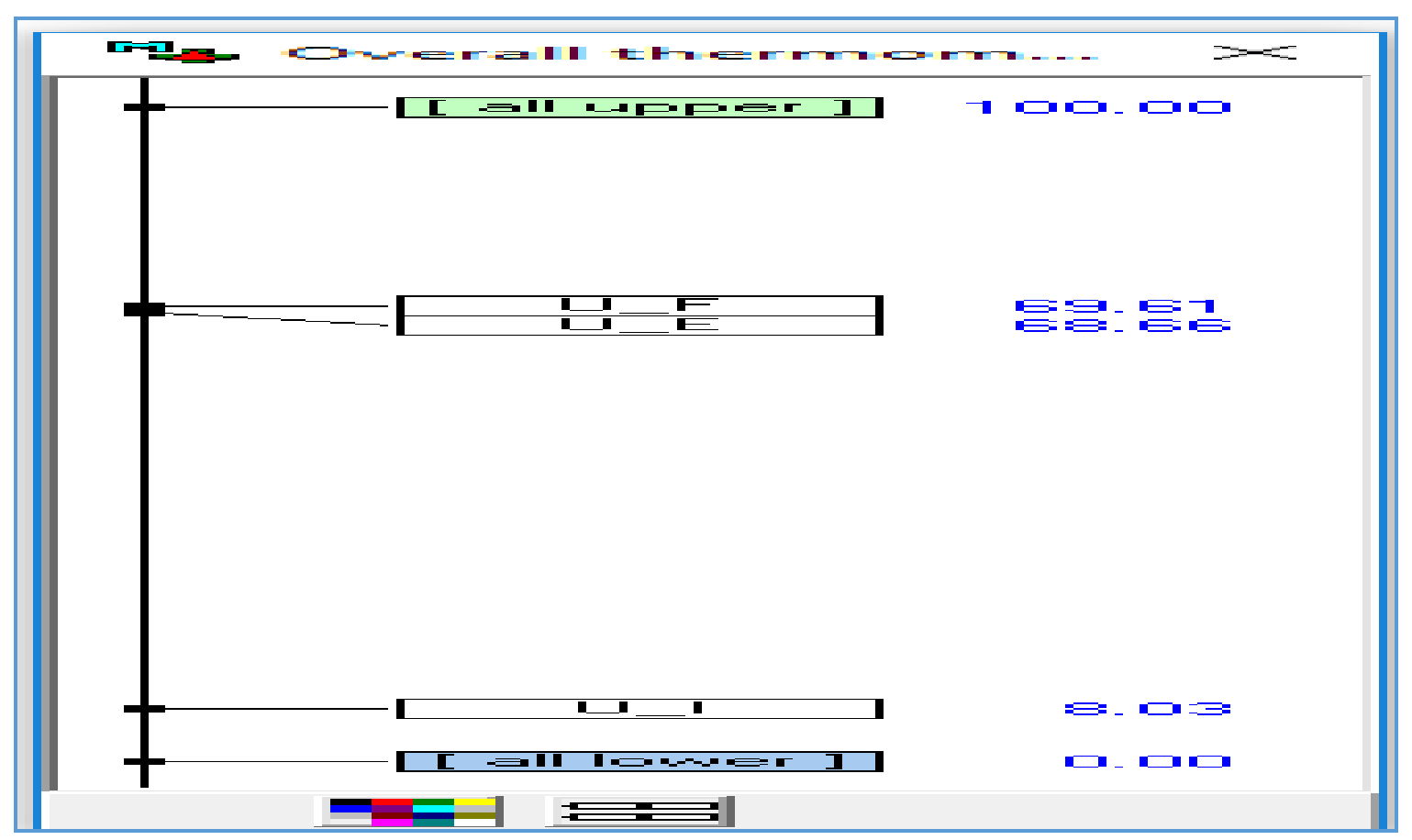

Figure 12. Overall Thermometer

The concept of sub-importance each candidate gives to a specific criterion is depicted in the bar-graph of performance relating to the prospective options (U-F, U-E, U-I). Taking into consideration the bar-graphs and the University profiles we notice that U-F has achieved the highest relatively score in two criteria: k2-University Reputation, k3-Logistics Infrastructure and falls short with almost the same scoring in criteria k1 and k4. Although U-A has achieved the highest score in one criterion k4-Interconnections with other Universities and Academic Institutions and reached excellence in $\mathrm{k} 1$ - cost of undergraduate studies, still falls short significantly in criteria k2 and k3 $(42,86)$. Finally U-I has zero scoring in $\mathrm{k} 2, \mathrm{k} 3$ and $\mathrm{k} 4$ and very low scoring in $\mathrm{k} 1(18,46)$. 


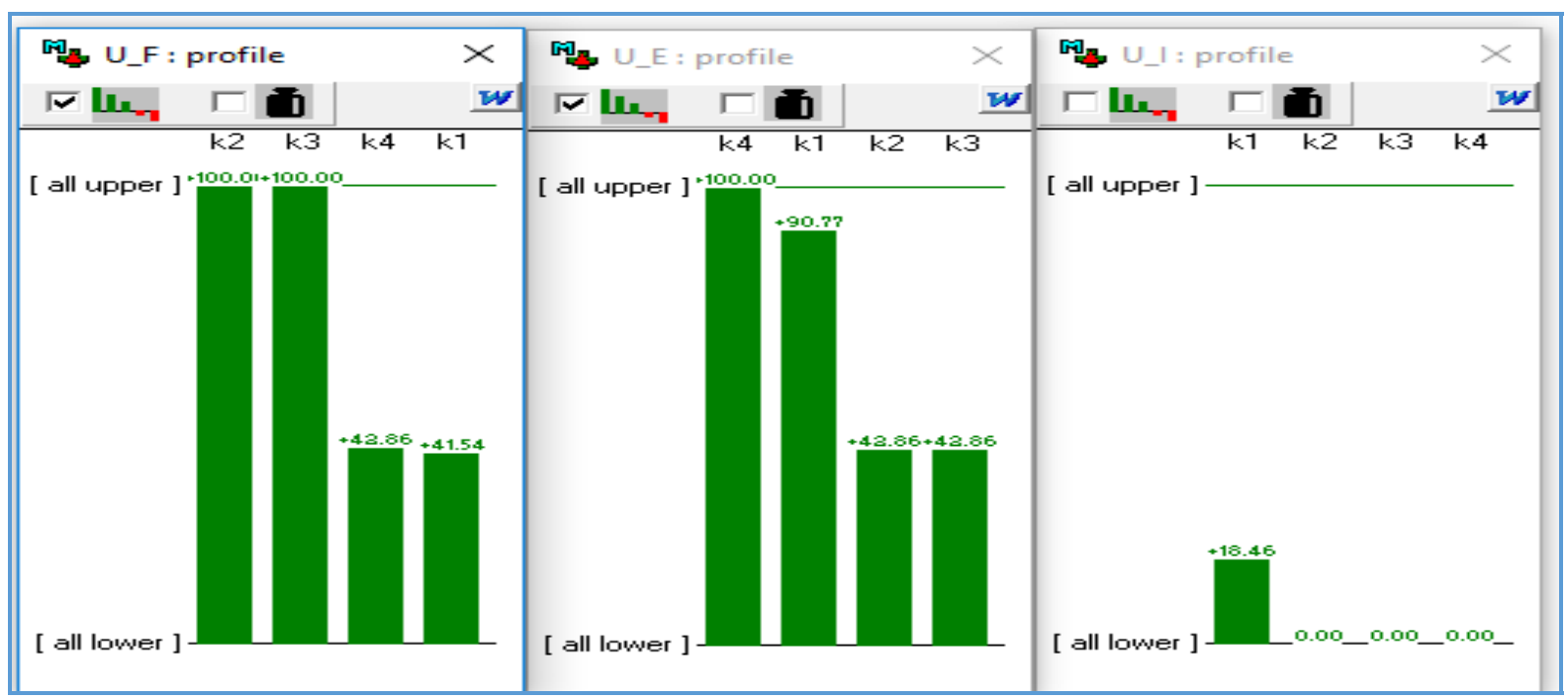

Figure 13. Profile U-F, U-E, U-I classified per criterion

In the following bar-graph (Figure 14) each bar of choice correlates to weight-result of the criterion and the University scoring U-F and U-E. Therefore the profile relating to weights represent the individual importance the scorings/ratings of each criterion holds in relation to the overall scoring of the criterion and this is depicted in the upper part of the bar-graph, which in our case is 69,61 and 68,66 respectively.

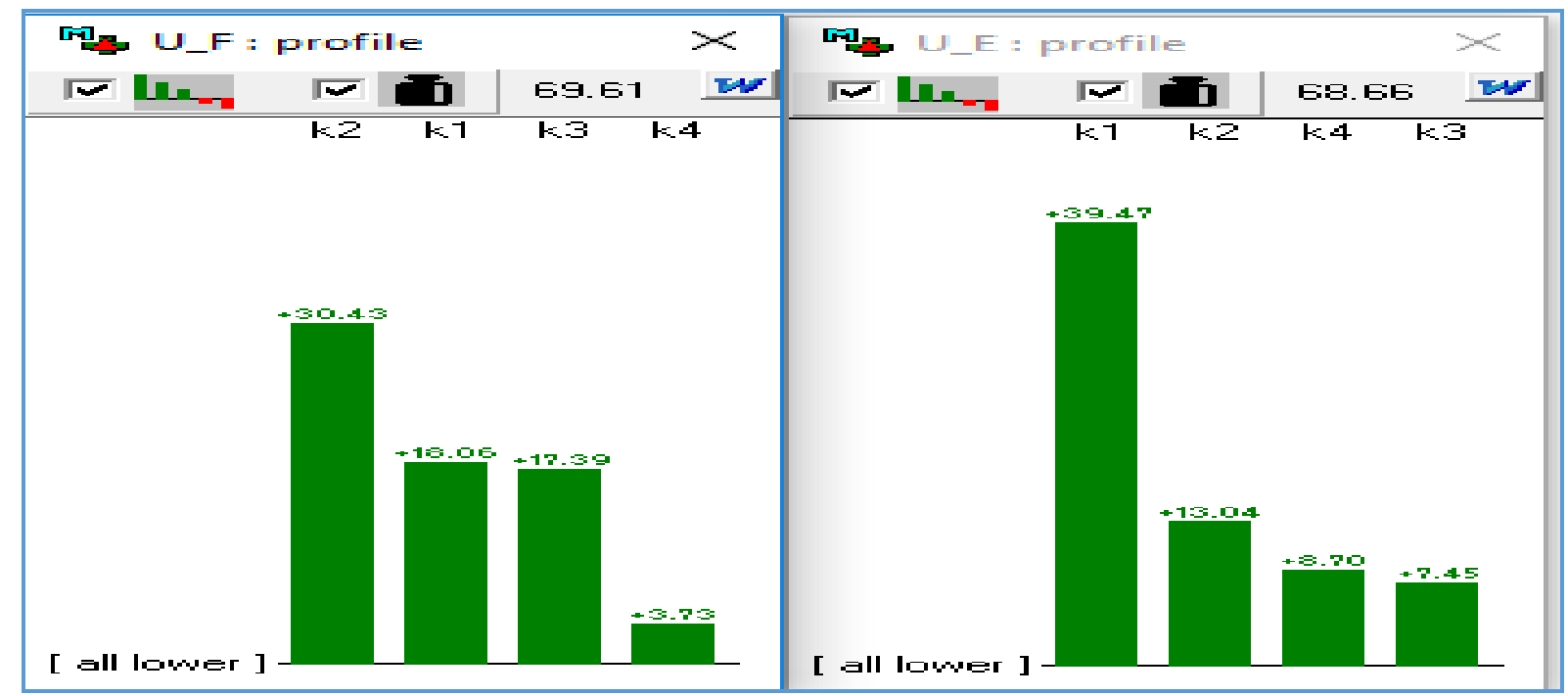

Figure 14. Bar-graph of U-F, U-E, U-I along with weights

Additionally, on evaluating the results the computer software enables us to compare the first and second candidate Universities U-F and U-E. The positive differences depicted in green color in the first bar-graph, denote the criteria $(\mathrm{k} 2, \mathrm{k} 3)$ for which the first University beats per 


\section{Macrothink}

Case Studies in Business and Management

ISSN 2333-3324

2017, Vol. 4, No. 2

choice the second. Orange color is used to specify the criteria $(\mathrm{k} 1, \mathrm{k} 4)$ in the bar- graph with which U-E is better than U-F (Figure 15).

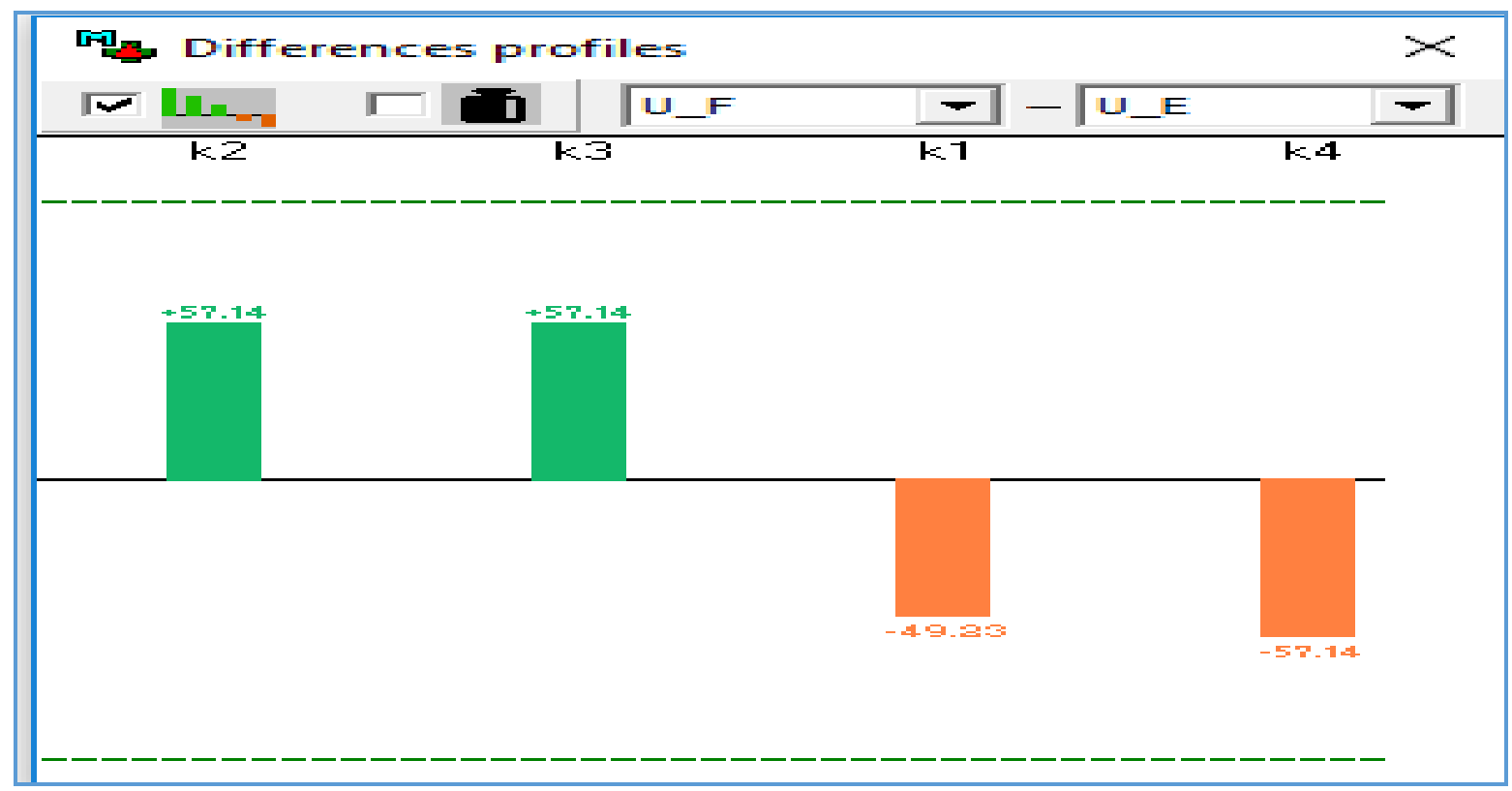

Figure 15. Bar-graph differences of U-F and U-E

What follows is the bar-graph (Figure 16) with the weighted bars that enables us to analyze the range in which the differences counterbalance or not in favor of the first choice that is U-F or the second choice U-E. The total is shown automatically on the top right part of the bar-graph and is 0,95 .

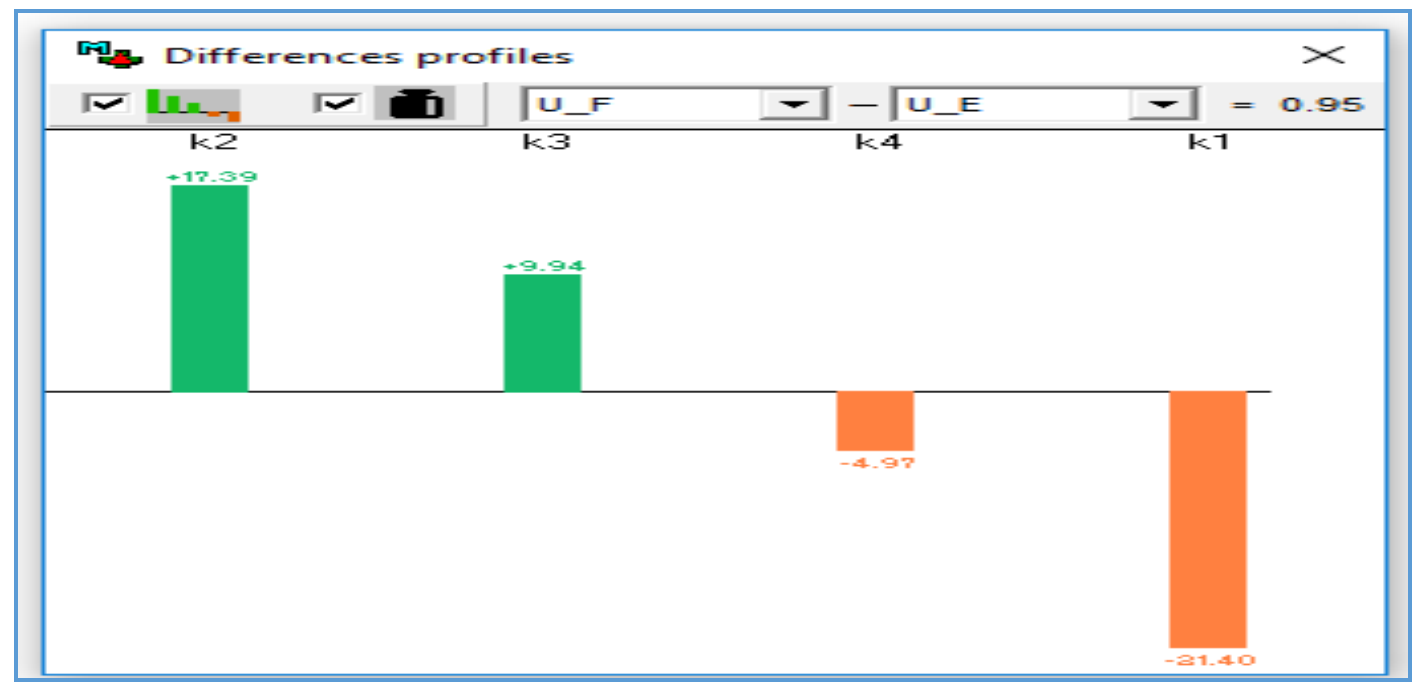

Figure 16. Bar-graph of differences of U-F, U-E with weights 


\section{Macrothink}

Case Studies in Business and Management

ISSN 2333-3324

2017, Vol. 4, No. 2

The software enables us to observe the outcome of the model in graphic representations in the form of XY Map. These graphic representations help us compare the scores of choices in two criteria or group criteria. At the same time the effective border for each case we examined, is depicted by the red line with all the efficient solutions. Some indicative combinations are presented in the following Figures 17, 18, 19.

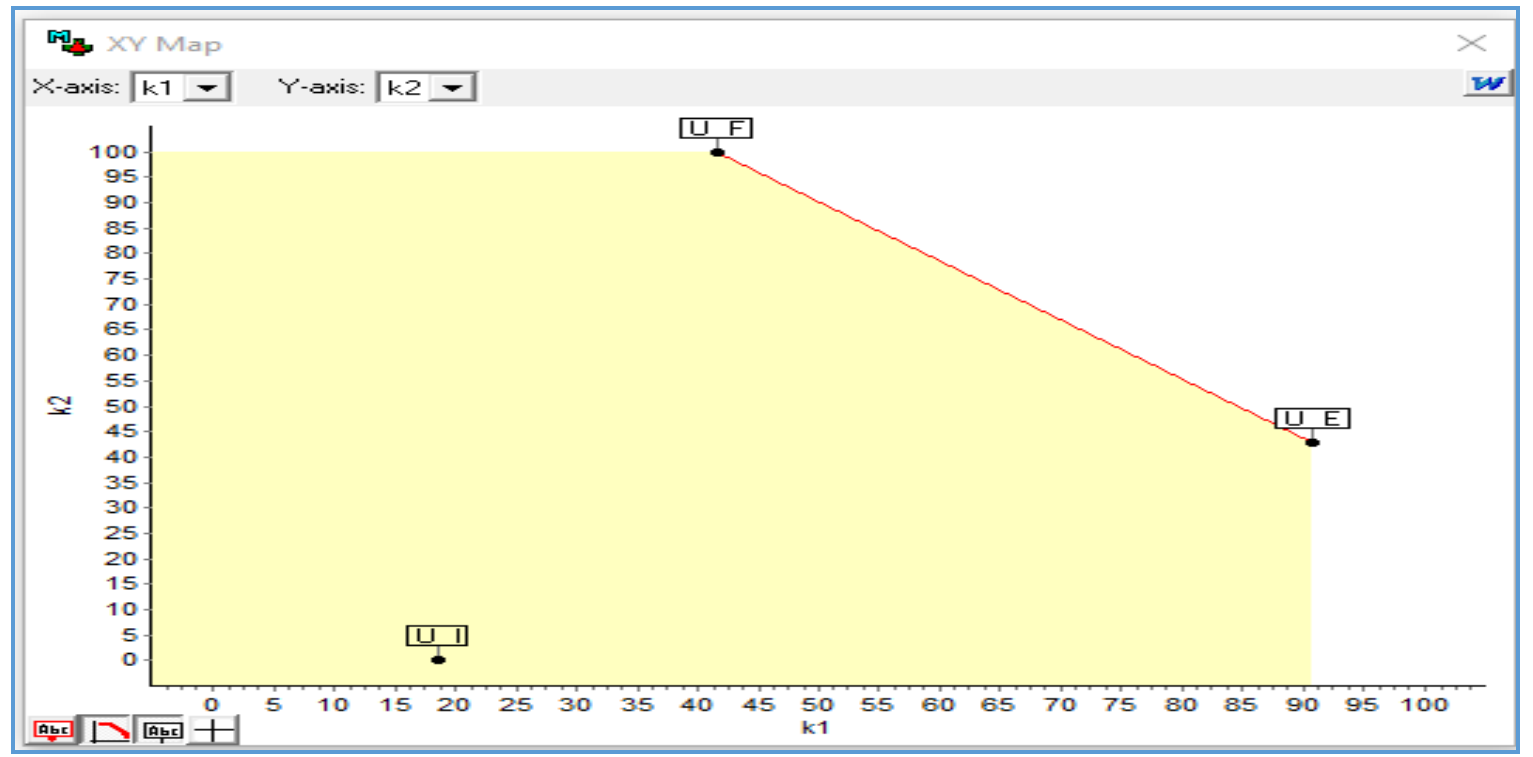

Figure 17. Graphic depiction of the cost criterion $\mathrm{k} 1$ in relation to the reputation criterion $\mathrm{k} 2$

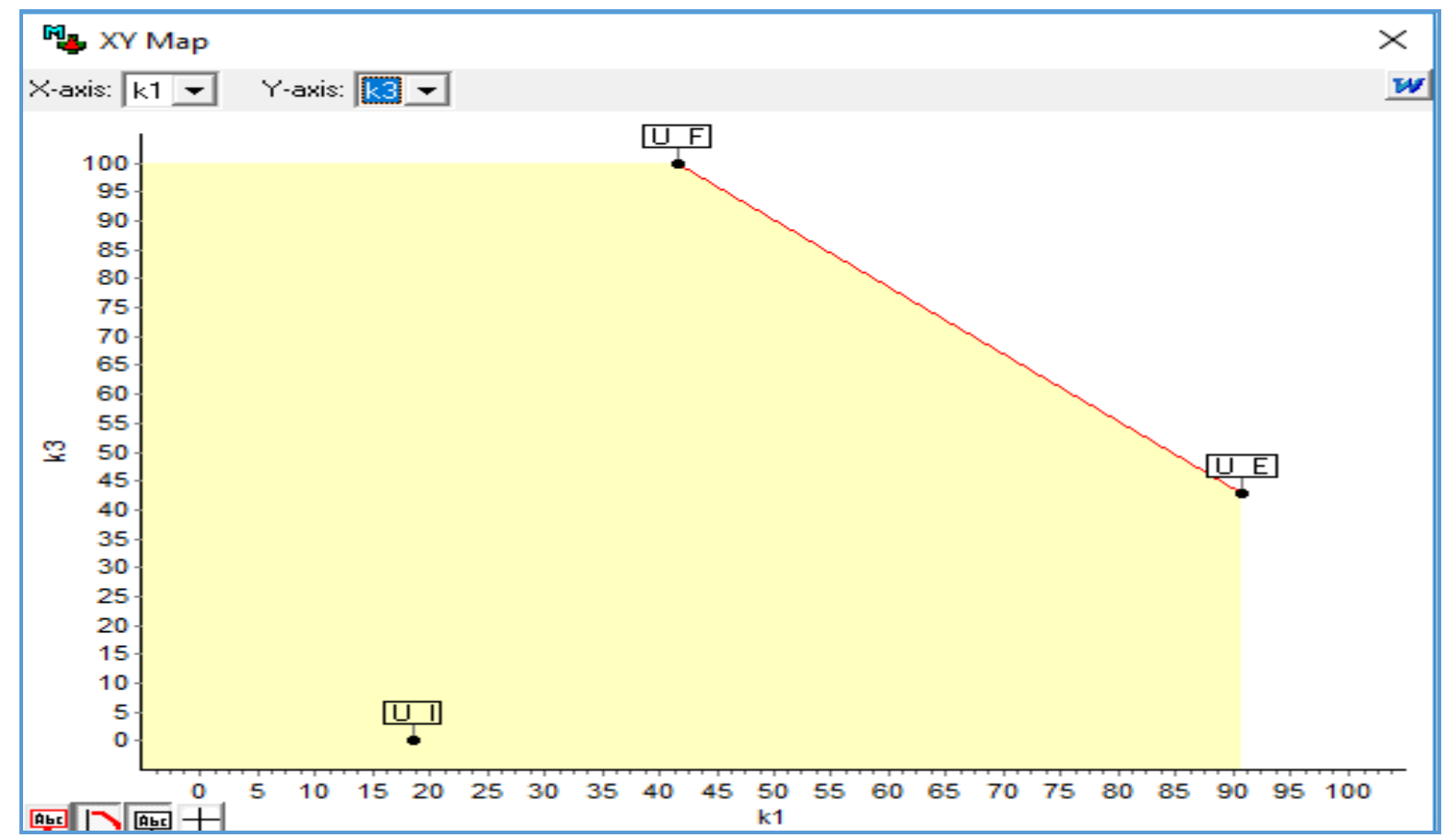

Figure 18. Graphic depiction of the infrastructure criterion $\mathrm{k} 3$ in relation to the cost criterion k1 


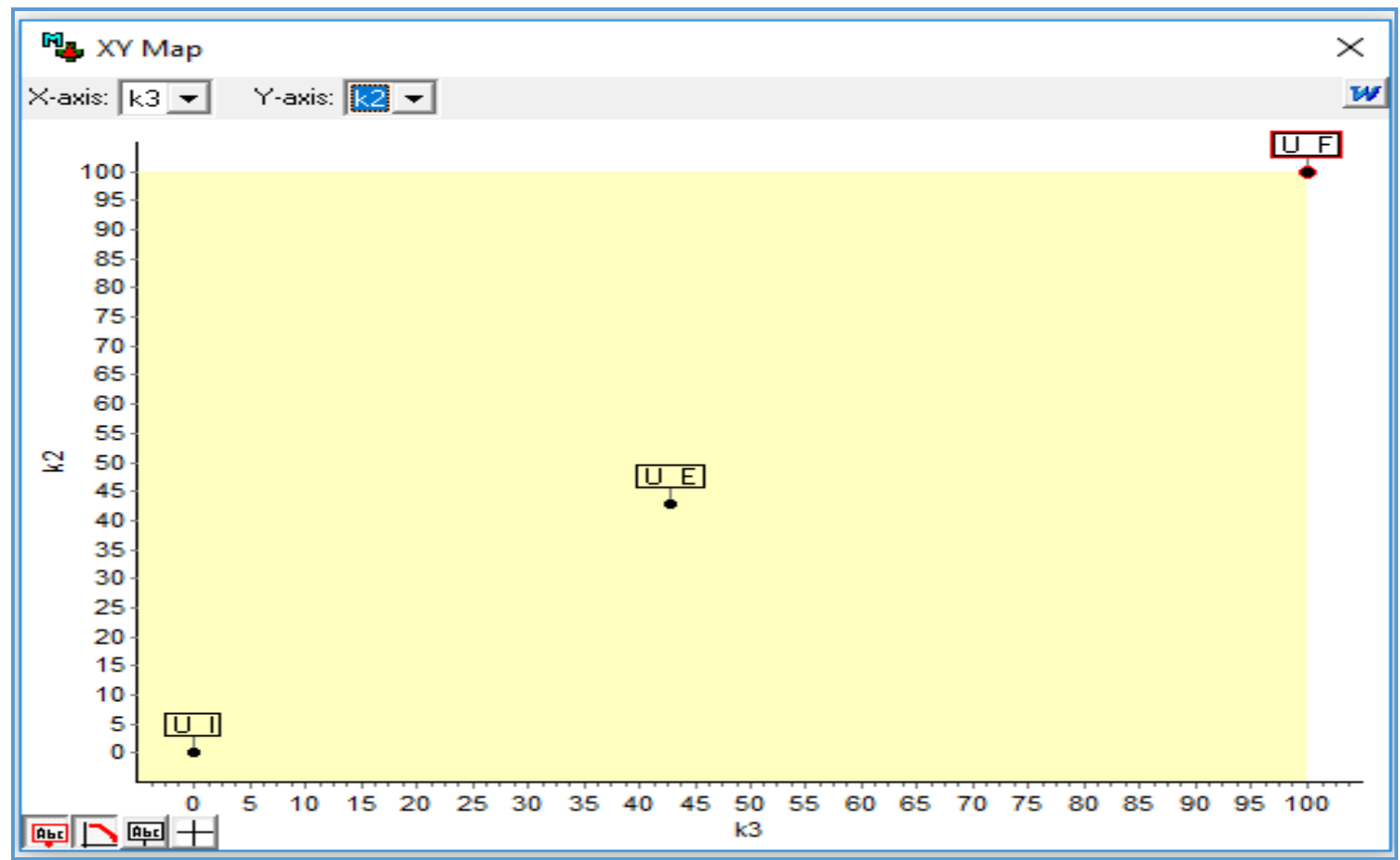

Figure 19. Graphic depiction of the infrastructure criterion $\mathrm{k} 3$ in relation to the reputation criterion $\mathrm{k} 2$

\subsection{Sensitivity Analysis}

This kind of analysis allows us to detect how the rate of each criterion changes when the total value of the options changes. Its application to one criterion gives us the visual perception of the range, the width, in which the model's suggestion would change as a result of the changes occurring at the expense of the criterion.

The line of each choice in the graph shows the differential in the total scores of the choices, when the weight of the criterion ranges from 0 to $100 \%$. The vertical red line represents the current weight of the criterion (Figures 20, 21, 22, 23). 


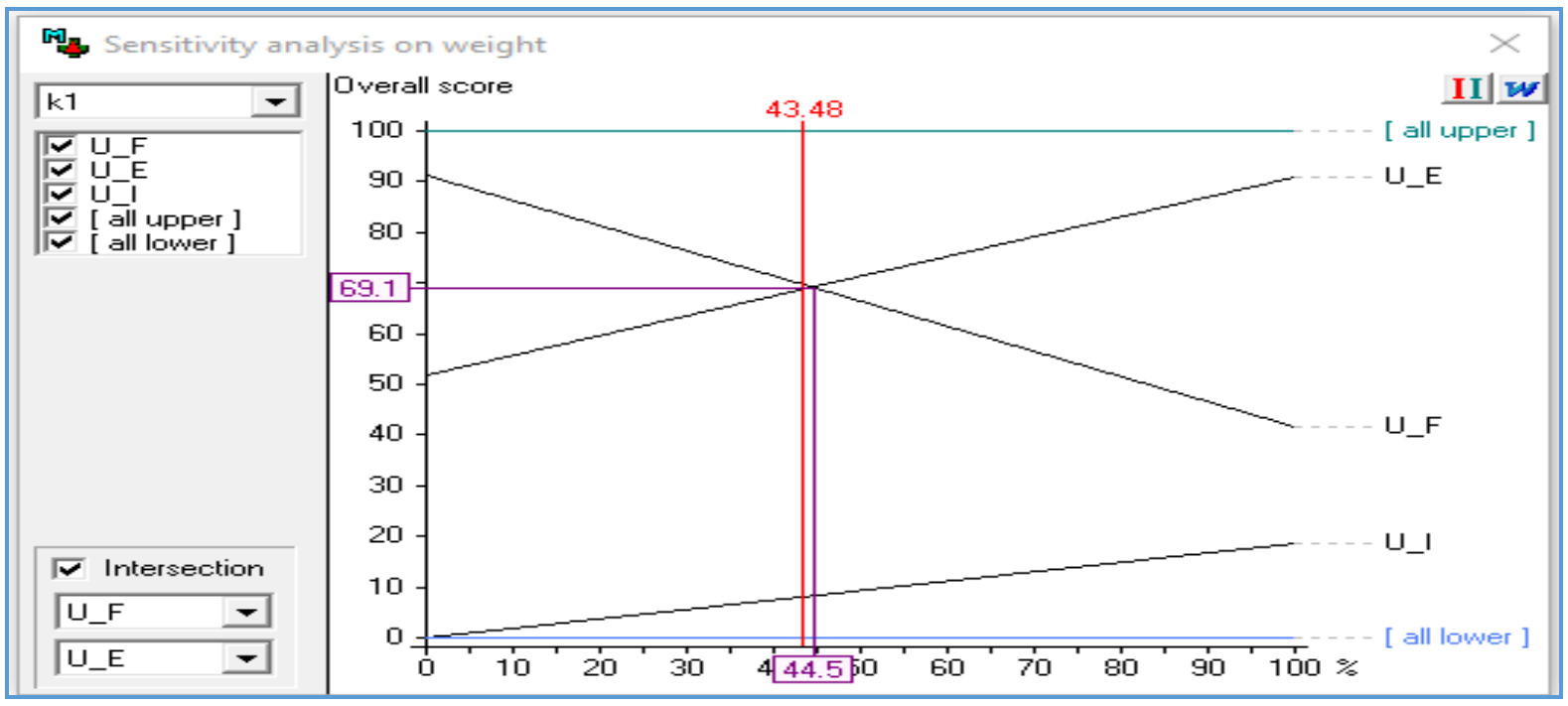

Figure 20. Sensitivity analysis concerning the cost criterion

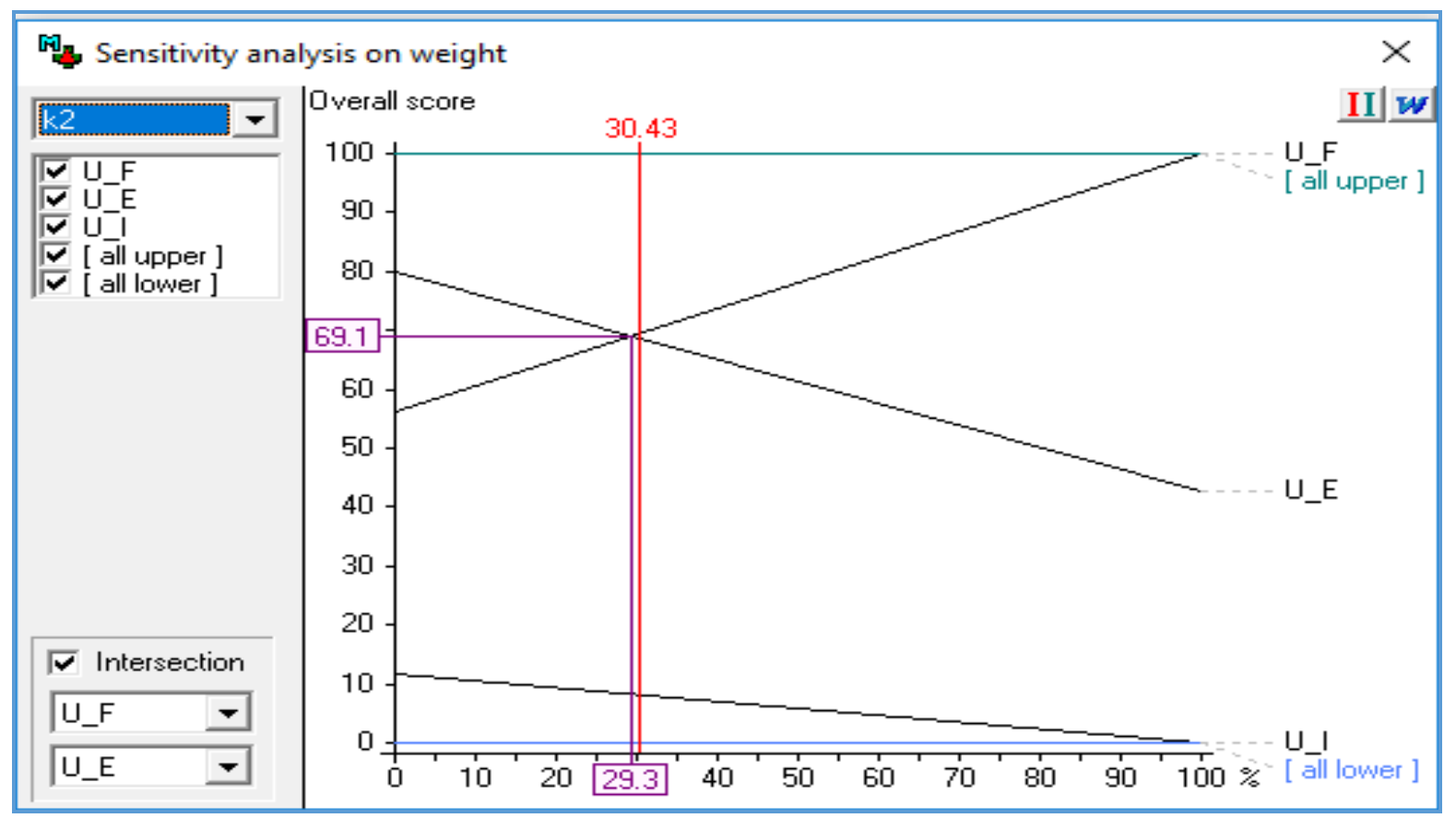

Figure 21. Sensitivity analysis of the reputation criterion 


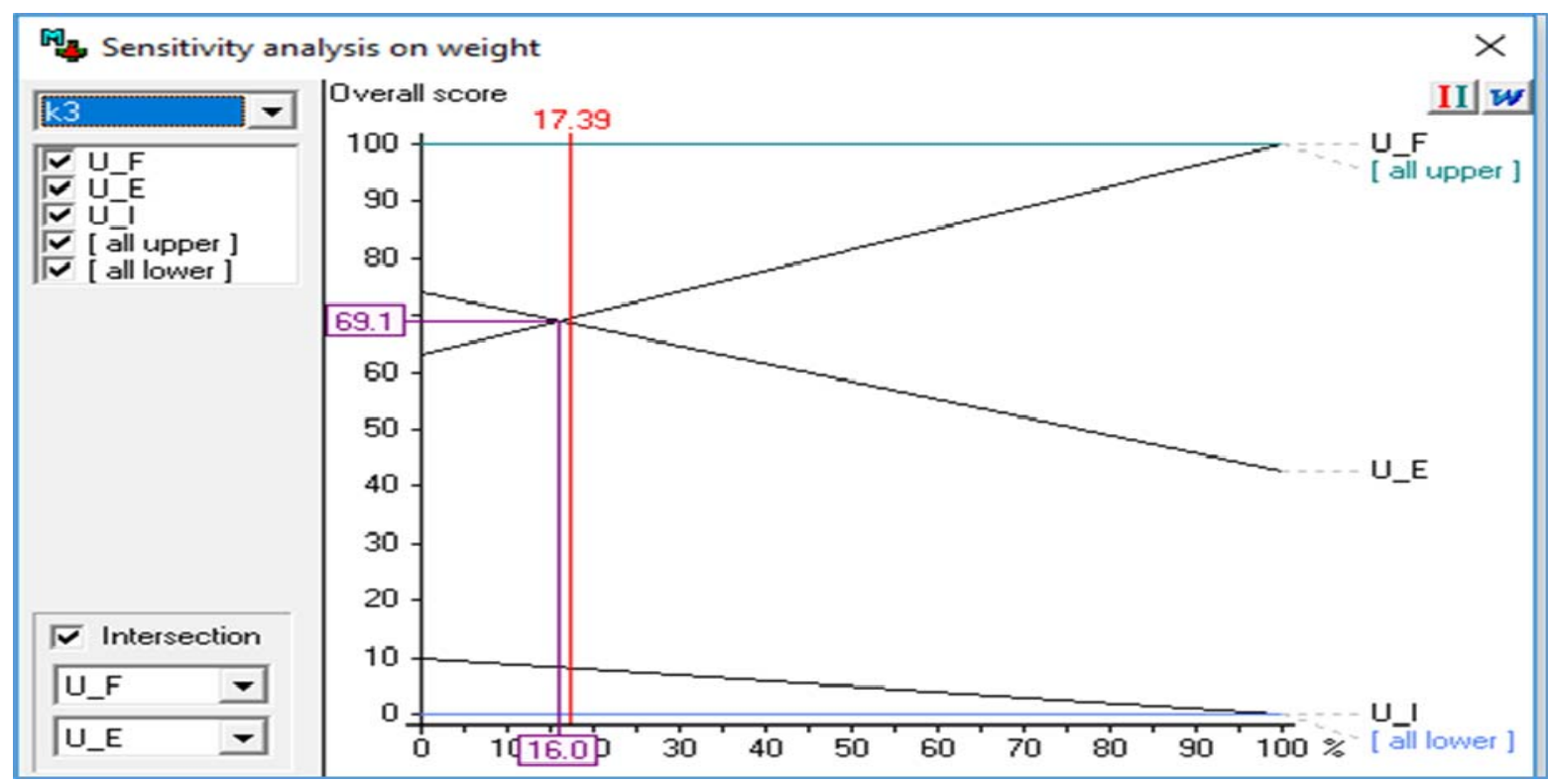

Figure 22. Sensitivity analysis of the logistics-infrastructure criterion

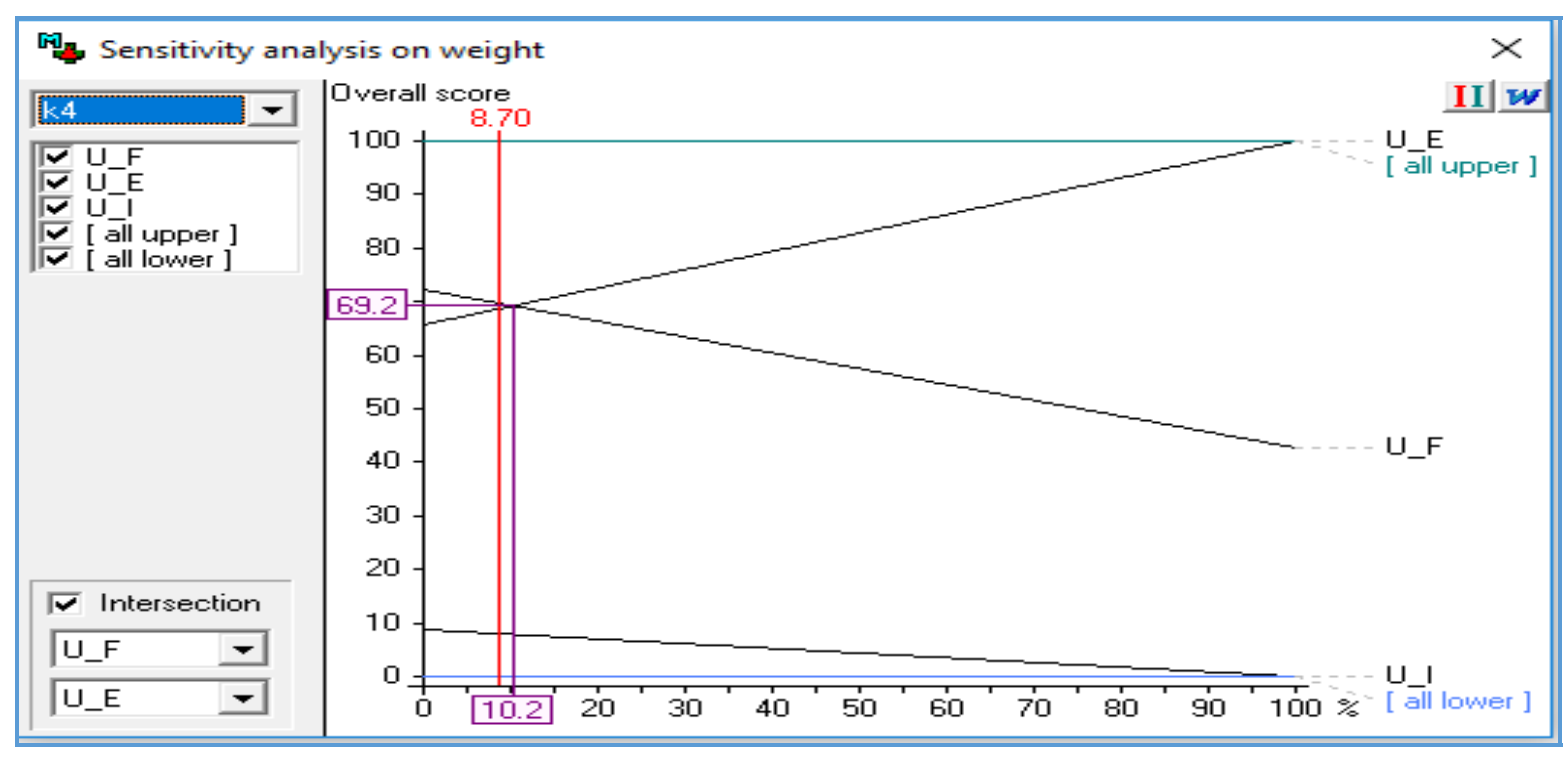

Figure 23. Sensitivity analysis of the logistics-infrastructure criterion

The detection of weight which causes change in the classification of total attractiveness with the use of sensitivity analysis of U-F and U-E in the criterion of cost of undergraduate studies can be analyzed in the following way:

The overall scores are crossed on the point 44, 5 and 69,1 . This indicates that the lesser the weight is given on $\mathrm{k} 1$ than 44.5 , the better scoring U-F will get. However, if the weight given on the cost increases over 44.5 then the U-F will receive better total scoring. If the lines of two options are not crossed, the one option is always more attractive than the other, whatever weight might be given to them. We can make relative comparisons with other criteria 


\section{Macrothink

respectively.

\subsection{Robustness Analysis}

When taking decisions it would be useful to define the range of making deductions of the quantity of the information due to different degree of inaccuracy or uncertainty. This is due to the fact that when making deductions the decision-taking process often leads to uncertain, inaccurate or incomplete information that is why the Robustness analysis is recommended.

In this kind of analysis the triangle symbolizes dominance, that is when one option dominates over the other, when the former is as attractive as the latter in terms of the criteria but the former is more attractive than the other in at least one criterion.

The symbol of the cross ( $\boldsymbol{t}^{4}$ ) symbolizes dominance, that is when one option dominates over the other, when the former is as attractive as the latter in terms of the criteria but the former is more attractive than the other in at least one criterion. As shown in Figure 24, the M-MACBETH software organizes the incoming model information into 3 types:

- Ordinal,

- $\mathrm{MACBETH} \mathrm{\kappa \alpha l}$

- cardinal

and two areas:

- (local) and

- global information.

The ordinal information refers only to the classification excluding whatever information is characterized by differences of attractiveness. Macbeth information consists of conceptual judgments that are introduced to the model and it does not disassociate possible numerical scales which are compatible with these judgments. On the contrary, the cardinal information denotes the precise, accurate numerical scale evaluated by the analyst. The local information is all the information specifically for only one criterion whereas the global refers to the weights of the model.

The robustness analysis along with the ordinal, the MACBETH, the cardinal, the global and local information confirms the additive dominance of U-F in relation to the rest. 


\section{MInstitute ${ }^{\text {Mit }}$}

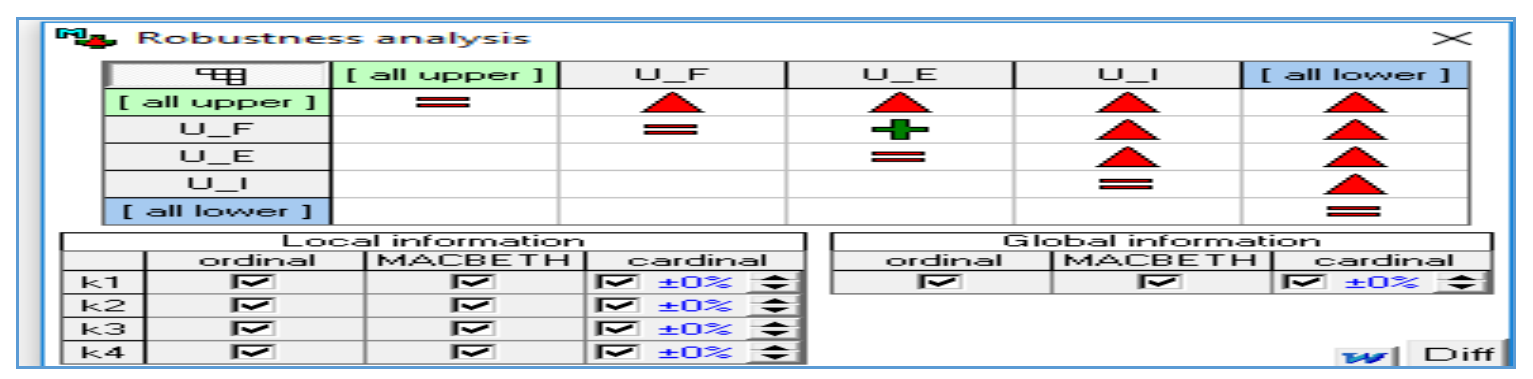

Figure 24. Robustness analysis (ordinal \& MACBETH global-ordinal \& MACBETH local information)

\section{Conclusions}

The present article attempted to develop the methods and support the techniques that will help students take the optimal decision taking advantage of the information available along with the use of multicriteria analysis of decisions. The development of skills in decision-taking is one of the most difficult problems concerning students that have to be tackled in this stage of their life.

The student who has all this information can assess and evaluate all the possible outcomes of his/her options and can process the importance of various options so as to choose the best solution. One crucial decision students of secondary education are asked to take is what kind of educational, occupational studies they will follow, what career to choose. Choosing to further one's education by attending a University abroad for undergraduate studies is a complex process since multidimensional decisions have to be taken in that respect.

We examined a specific case of a student, Eva, who chooses the University of France via the application of MACBETH software. For this specific study, the factors of greatest importance that lead to choosing the University Eva finally chose, were four, the cost of undergraduate studies, the reputation-status of the University, its logistics and infrastructure and its interconnections with other Universities and other Academic Institutions. MACBETH software is a clever and relatively practical tool for making decisions simple or complex in the field of multicriteria analysis. It is worth mentioning also that this software is a very useful tool, enabling the decision-maker in registering, evaluating and analyzing the options based on choice-criteria depending on the each case every time. The education received by undergraduate studies is a long lasting process which requires great commitment on the part of the prospective candidates in universities so that this (education) is substantial and effective for their future career and is therefore defined by many factors.

There is an abundance of software in the field of multicriteria analysis, which are used as useful tools in decision making. We have to take into account though that the way we take decisions does not follow the same pattern and the person who decides has always the last word since there are suitable and unsuitable methods in relation to the problem, the data and the people involved. The analyst should register, analyze, evaluate each possible consequence for each possible outcome, each choice criterion for alternative solutions and actions relating to the problem. 


\section{References}

Anwar, A., Bwisa, H., Otieno, R., \& Karanja, K. (2014). Strategic Decision Making: Process, Models, and Theories. Business Management and Strategy, 5(1), 78-104. https://doi.org/10.5296/bms.v5i1.5267

Bana e Costa, C. A., \& Vansnick, J. C. (1994). MACBETH: An interactive path towards the construction of cardinal value functions. International Transactions in Operations Research, 1(4), 488-500. https://doi.org/10.1111/j.1475-3995.1994.00325.x

Bana e Costa, C. A., \& Vansnick, J. C. (1999). The MACBETH approach: Basic ideas, software, and an application. In N. Meskens \& M. Roubens (Eds.), Advances in Decision Analysis (pp. 135-152). Dordrecht, Netherlands: Springer. https://doi.org/10.1007/978-94-017-0647-6_9

Bana e Costa, C. A., De Corte, J. M., \& Vansnick, J. C. (2005). On the mathematical foundations of MACBETH. In J. Figueira, S. Greco, \& M. Ehrgott (Eds.), Multiple Criteria Decision Analysis: The State of the Art Surveys (pp. 409-442). New York, Philadelphia USA: Springer. https://doi.org/10.1007/0-387-23081-5_10

Belton, V., \& Stewart T. (2002). Multiple criteria decision analysis: An integrated approach. Dordrecht, Netherlands: Kluwer Academic Publishers. https://doi.org/10.1007/978-1-4615-1495-4

Bouyssou, D., Marchant, T., Pirlot, M., Perny, P., Tsoukiàs, A., \& Vincke, Ph. (2000). Evaluation and Decision Model. A Critical Perspective. Dordrecht, Netherlands: Kluwer Academic Publishers. https://doi.org/10.1007/978-1-4615-1593-7

Crites, J., \& Savickas, M. (1995). Career Maturity Inventory. California, USA: McGraw-Hill Inc.

David, F. R. (2009). Strategic Management: Concepts and Cases. Upper Saddle River, NJ: Prentice Hall.

De Lima, A., \& Damiani, J. H. (2009). Proposed Method for Modeling Research and Development, $(R \& D)$ Project Prioritization Criteria. PICMENT 2009 Proceedings, August 2-6, Portland, Oregon USA.

Enns, H., \& McFarlin, D. (2003). When executives influence peers: does function matter?. Human Resource Management, 42(2), 125-142. https://doi.org/10.1002/hrm.10072

Fernandez-Huerga, E. (2008). The economic behavior of human beings: the institutional/post-Keynesian model. Journal of Economics Issues, 42(3), 709-726. https://doi.org/10.1080/00213624.2008.11507175

Figueira, J., \& Roy, B. (2002). Determining the weights of criteria in the ELECTRE type methods with a revised Simos procedure. European Journal of Operational Research, 139, 317-326. https://doi.org/10.1016/S0377-2217(01)00370-8

Franco, L. A., \& Montibeller, G. (2010). Facilitated modelling in operational research. 
European Journal of Operational Research, 205(3), 489-500. https://doi.org/10.1016/j.ejor.2009.09.030

Franco, L. A., \& Rouwette, E. A. J. A. (2011). Decision development in facilitated modelling workshops. European Journal of Operational Research, 212(1), 164-178. https://doi.org/10.1016/j.ejor.2011.01.039

Gati, I. (1986). Making career decisions: A sequential elimination approach. Journal of Counseling Psychology, 33, 408-417. https://doi.org/10.1037/0022-0167.33.4.408

Gelatt, H. (1962). Decision Making: A Conceptual Frame of Reference for Counseling. Journal of Counseling Psychology, 9, 240-245. https://doi.org/10.1037/h0046720

Goldstein, W. M., \& Hogarth, R. M. (1997). Judgment and decision research: Some historical context. In W. M. Goldstein \& R. M. Hogarth (Eds.), Research on Judgment and Decision Making: Currents, Connections, and Controversies (pp. 3-65). Cambridge UK: Cambridge University Press.

Harren, V. (1979). A model for career decision making for college students. Journal of Vocational Behavior, 14, 119-133. https://doi.org/10.1016/0001-8791(79)90065-4

Hilton, T. (1962). Career decision making. Journal of Counseling Psychology, 9(4), 291-298. https://doi.org/10.1037/h0048309

Hokkanen, J., \& Salminen, P. (1997). Choosing a solid waste management system using multicriteria decision analysis. European Journal of Operational Research, 98(1), 19-36. https://doi.org/10.1016/0377-2217(95)00325-8

Hwang, Ch. L., \& Yoon, K. (1981). Methods for Multiple Attribute Decision Making. Multiple Attribute Decision Making (pp. 58-191). Berlin Heidelberg, Germany: Springer. https://doi.org/10.1007/978-3-642-48318-9

Kaldor, D., \& Zytowsky, D. (1969). A maximizing model of occupational decision making. $\begin{array}{llll}\text { Personnel and } \quad \text { Guidance } & \text { J8urnal, }\end{array}$ https://doi.org/10.1002/j.2164-4918.1969.tb03006.x

Karamanis, K., \& Hyz, A. (2016). How Flexible Working Influence Unemployment? Evidence from Greek Labour Market. A New Growth Model for the Greek Economy: Requirements for Long-Term Sustainability (pp. 235-249). Palgrave MacMillan USA.

Katz, M. (1963). Decisions and values. A rationale for secondary school guidance. College Entrance Examination Board, New York, USA.

La Scalia, G., Marra F. P., Rühl, J., Sciortino, R., \& Caruso, T. (2016). A fuzzy multi-criteria decision-making methodology to optimise olive agro-engineering processes based on geo-spatial technologies. Int. J. of Management and Decision Making, 15(1), 1-15.

Lahdelma, P. S., \& Hokkanen, J. (2002). Locating a waste treatment facility by using stochastic multicriteria acceptability analysis with ordinal criteria. European Journal of Operational Research, 142, 345-356. https://doi.org/10.1016/S0377-2217(01)00303-4 
Leong, S., Leong F., \& Hoffman, M. (1987). Counseling expectations of rational, intuitive, and dependent decision makers. Journal of Counseling Psychology, 34(3), 260-265. https://doi.org/10.1037/0022-0167.34.3.261

Li, Sh., \& Davies, B. J. (2001). Key issues in using information systems for strategic marketing decisions. Int. J. of Management and Decision Making, 2(1), 16-34. https://doi.org/10.1504/IJMDM.2001.001219

Manski, Ch. F. (1980). An empirical analysis of household choice among motor vehicles. Transportation Research Part A: General, 14(1-2), 349-366. https://doi.org/10.1016/0191-2607(80)90054-0

Manski, Ch. F. (2004). Measuring Expectations. Econometrica, 72(5), 1329-1376. https://doi.org/10.1111/j.1468-0262.2004.00537.x

Mcfadden, D. (1981). Econometric Models for Probabilistic Choice Among Products. The Journal of Business, 53(3), S13-S29.

Montibeller, G., \& Franco, L. A. (2011). Raising the bar: Strategic multi-criteria decision analysis. Journal of the Operational Research Society, 62(5), 855-867. https://doi.org/10.1057/jors.2009.178

Mousiolis, D., Zaridis, A., Karamanis, K., \& Rontogianni, A. (2015). Corporate Social Responsibility in SMEs and MNEs. The Different Strategic Decision Making. Procedia-Social and Behavioral Sciences, 175, 579-583. https://doi.org/10.1016/j.sbspro.2015.01.1240

Nijkamp, P., Torrieri, F., \& Vreeker R. (2002). A decision support system for assessing alternative projects for the design of a new road network: Methodology and application of a case study. Int. J. of Management and Decision Making, 3(2), 114-138. https://doi.org/10.1504/IJMDM.2002.002468

Nikolopoulos, A. (2003). Assessing subjective influences on managerial decisions. Int. J. of Management and Decision Making, 3(3/4), 337-352. https://doi.org/10.1504/IJMDM.2002.002482

Phillips, T. L., Peppers, R. A., \& DeMichele, D. W. (1985). Stratigraphic and interregional changes in Pennsylvania coal-swamp vegetation: Environmental influences. International Journal of Goal Geology, 5, 43-109. https://doi.org/10.1016/0166-5162(85)90010-2

Richard, J. L. (1981). Aid to the strategic decision in SMES. In E. Jacquet-Lagrèze \& J. Siskos (Eds.), Method of Multicriteria Decision (pp. 119-142). Paris: Men and techniques.

Rocha, H., \& Ghoshal, S. (2006). Beyond self-interest revisited. Journal of Management Studies, 43(3), 585-619. https://doi.org/10.1111/j.1467-6486.2006.00603.x

Rosenhead, J. (1996). What's the problem? An introduction to structuring to methods. Interfaces, 26(6), 117-131. https://doi.org/10.1287/inte.26.6.117

Roy, B. (1985). Multicriteria Methodology: To aid in the decision. Paris: Economica. 
Roy, B., \& Bouyssou, D. (1993). Multicriteria support to the decision: Methods and Case. Paris: Economica.

Sahinidis, A., Vassiliou, E., \& Hyz, A. (2014). Factors Affecting Entrepreneurs' Intention to Start a New Venture: An Empirical Study. International Journal on Strategic Innovative Marketing, 1, 148-162.

Siskos, Y., \& Spyridakos, A. (1999). Intelligent multicriteria decision support: Overview and perspectives. European Journal of Operational Research, 113, 236-246. https://doi.org/10.1016/S0377-2217(98)00213-6

Siskos, Y., Grigoroudis, E., \& Matsatsinis, N. F. (2005). UTA methods, In Multiple Criteria Decision Analysis: State of the Art Surveys. In J. Figuera, S. Greco, \& M. Ehrgott (Eds.), International Series in Operations Research Management Science (pp. 297-343). New York, Philadelphia USA: Springer.

Super, D., Savickas, M., \& Super, C. (1996). The life-span, life-space approach to careers. In Brown, Brooks \& Associates (Eds.), Career Choice \& Development (3rd ed., pp. 121-178). San Francisco, USA: Jossey Bass.

Tiedeman, D., \& O'Hara, R. (1963). Career development, choice and adjustment. College Entrance Examination Board, New York, USA.

Vroom, V. (1964). Work and motivation. New York, USA: John Wiley \& Sons, Inc.

Yip, J. A., \& Côté, S. (2013). The emotionally intelligent decision maker: Emotion - understanding ability reduces the effect of incidental anxiety on risk taking. Psychological Science, 24, 48-55. https://doi.org/10.1177/0956797612450031

Zeelenberg, M., Nelissen, R. M. A., Breugelmans, S. M., \& Pieters, R. (2008). On emotion specificity in decision making: Why feeling is for doing. Judgment and Decision Making, 3, $18-27$.

Zeelenberg, M., Van Dijk, W. W., Van der Pligt, J., Manstead, A. S. R., Van Empelen, P., \& Reinderman, D. (1998). Emotional reactions to the outcomes of decisions: The role of counterfactual thought in the experience of regret and disappointment. Organizational Behavior and Human Decision Processes, 75, 117-141. https://doi.org/10.1006/obhd.1998.2784

\section{Copyright Disclaimer}

Copyright for this article is retained by the author(s), with first publication rights granted to the journal.

This is an open-access article distributed under the terms and conditions of the Creative Commons Attribution license (http://creativecommons.org/licenses/by/3.0/). 